\title{
Assessment of a stirred-cell reactor operated semi-continuously for the kinetic study of fast direct ozonation reactions by reactive absorption.
}

\author{
Thom Thi DANG ${ }^{\mathrm{a}}$, Pierre-François BIARD ${ }^{\mathrm{a}^{*}}$, Annabelle COUVERT ${ }^{\mathrm{a}}$ \\ aÉcole Nationale Supérieure de Chimie de Rennes, CNRS, UMR 6226, 11 Allée de Beaulieu, CS 50837, \\ 35708 Rennes Cedex 7, France \\ *Corresponding author: pierre-francois.biard@ensc-rennes.fr
}

\begin{abstract}
A jacketed stirred-cell reactor, operated semi-continuously, was used to assess the kinetics of fast ozonation reactions by reactive absorption. The method was applied to the direct ozone reaction with resorcinol. A high resorcinol concentration was used to reach a steady state and to neglect the byproducts accumulation. Thus, the mass-transfer rate, and consecutively the reaction rate, were deduced from the ozone mass balance in the gas phase. The gas-phase and liquid-phase mass-transfer coefficients were previously measured directly through the ozone absorption in appropriated conditions. The results emphasized the high sensitivity of the reaction rate constant to the ozone physicochemical properties, especially its solubility, which is controversial in the literature. Therefore, several correlations used to calculate the ozone solubility in water were considered to calculate the second-order reaction rate constant, which varied from $3.57-4.6810^{5} \mathrm{~L} \mathrm{~mol}^{-1} \mathrm{~s}^{-1}$ at $20^{\circ} \mathrm{C}$ to $9.50-12.210^{5} \mathrm{~L} \mathrm{~mol}^{-1} \mathrm{~s}^{-1}$ at $35^{\circ} \mathrm{C}$. The activation energy was in the range $35-59 \mathrm{~kJ} \mathrm{~mol}^{-1}$ depending on the considered ozone solubility correlation. A sensitivity analysis is provided to assess the influence of the experimental conditions and ozone physicochemical properties on the model. Finally, the applicability of this method is thoroughly discussed.
\end{abstract}




\section{Introduction}

Ozone is widely used as an efficient and cost-effective oxidant and disinfectant in drinking and waste water treatments. ${ }^{1}$ Ozone reactivity in water is based on both direct reactions with molecular ozone and indirect reactions with various radicals formed during the ozone decomposition. ${ }^{1-3}$ Few experimental methods are suitable to determine the kinetics of direct ozone reactions. For relatively slow reactions, characterized by second-order reaction rate constants lower than $10^{2}-10^{3} \mathrm{~L} \mathrm{~mol}^{-1} \mathrm{~s}^{-1}$, the absolute method, using batch or continuous homogeneous reactors, should be applied. ${ }^{3}$ Nonetheless, such kinetic studies are complicated by both the low ozone stability, which makes the sampling method particularly sensitive, ${ }^{4}$ and low solubility in water. For faster reactions, homogeneous reactors are incompatible owing to the low ozone and/or reactant lifetimes except when using expensive systems such as a stopped-flow spectrophotometer. ${ }^{3}$ Instead, the competitive kinetic method is suitable but its accuracy depends on those of the selected reference compound kinetics.

Thus, heterogeneous gas-liquid reactors in which ozone is transferred in an aqueous solution containing the studied reactant must be applied alternatively. In this case, both mass-transfer and chemical reaction rates must be considered. The reaction rate constant is deduced from the so-called enhancement factor or reaction factor $E .^{3}$ This method, also called reactive absorption, is particularly suitable to evaluate the kinetics of direct reactions with molecular ozone since the ozone concentration in the liquid phase is usually negligible and not limited by the poor ozone solubility. This technique has been widely applied to determine reaction rate constants involved in chlorine hydrolysis, $\mathrm{H}_{2} \mathrm{~S}$ absorption in chlorine solution, flue desulfurization, NOx absorption or $\mathrm{CO}_{2}$ capture in amine solutions. ${ }^{5-16}$ Most of time, reactive absorption is applied using (i) batch reactors in which the gas and liquid phases are separated by a flat interface (stirred-cell reactor). The absorption rate, and consecutively the reaction rate, are deduced 
from the gas pressure decay over time; ${ }^{16}$ (ii) (semi) continuous reactors such as wetted-wall columns, wetted sphere, laminar jet absorbers, bubble columns (mechanically agitated or not). ${ }^{17}$

Reactive absorption has been also applied, especially by Beltrán and his coworkers, to assess the kinetics of several direct ozone reactions. ${ }^{3,18-21}$ Semi-batch (stirred or not) bubble columns were used most of time. Only a few studies were carried out in reactors in which the interfacial area is well defined such as stirred-cell reactors, wetted wall columns or wetted sphere absorbers. ${ }^{18,22-24}$ Even if stirred-cell reactors are currently operated batchwise measuring the pressure decay, semi-continuous operations with a continuous ozone gas flow were preferred in these studies. ${ }^{16}$ Stirred-cell reactors appear particularly appealing owing to their easy mathematical modeling, temperature control and flow patterns description. Nonetheless, the mass-transfer rate is low and the gas-side resistance might be significant, especially when a fast chemical reaction happens in the liquid phase. ${ }^{17}$ Liquid and gas mass-transfer performances of stirred cell reactors have been already documented in the literature. ${ }^{16,25,26}$

Reactive absorption is governed by the mass-transfer rate, which depends on the hydrodynamic and mass-transfer characteristics of the reactor, gas and liquid flow patterns, chemical reaction rate and stoichiometry, ozone solubility and diffusivity in both phases, as well as reactant diffusivity. ${ }^{15}$ Different kinetic regimes can be applied in reactive absorption. ${ }^{3,17,27,28}$ However, the pseudo-first order regime, in which the reactant concentration remains constant near the gas-liquid interface and equal to the bulk concentration, is recommended. In this case, the absorption rate is uninfluenced by the liquid masstransfer conductance $k_{L}$ and reactant diffusivity, allowing to decrease the number of model inputs and to improve the accuracy. Moreover, the absorbed solute concentration in solution is negligible and does not need measurement.

Rather low liquid reactant concentrations have been applied $\left(<10^{-3} \mathrm{~mol} \mathrm{~L}^{-1}\right)$ in ozonation studies, which leads to low enhancement factor $E$ and low ozone mass-transfer rate. ${ }^{18,19}$ Therefore, the ozone partial 
pressure at the contactor outlet was nearly identical to the inlet one, and only the reactant concentration decay over time was recorded to determine the mass-transfer and chemical reaction rates. However, this method can be biased by the influence of the by-products accumulating in solution. The purpose of this article is to demonstrate that higher reactant concentrations can be advantageously applied. In this case, the reactant concentration can remain constant over a sufficient duration to reach a steady state. The mass-transfer rate can be deduced from the ozone mass balance through the measurement of only the gas flow rate and both the inlet and outlet ozone concentrations using an online ozone analyzer. Furthermore, since the reactant concentration remains constant, the influence of the by-product is vanished.

A second aim of this article is to assess the high sensitivity of the reactive absorption method to the value of the ozone solubility (deduced from the ozone Henry's law constant), which is usually ignored in previous studies. However, the value of this ozone Henry's law constant is quite controversial in the literature, especially at temperatures higher than $25^{\circ} \mathrm{C}^{29}$

This method was applied to the resorcinol (m-dihydroxybenzene) oxidation kinetics for temperature ranging from 20 to $35^{\circ} \mathrm{C}$. Resorcinol is a massively used phenolic compound, suspected of being an endocrine disruptor based on its thyroid activity. ${ }^{30} \mathrm{~A} 2 \mathrm{~L}$ temperature controlled stirred-cell reactor operated semi-continuously was used for this purpose. The liquid volume, pressure, impellers position and stirring speed were kept identical. First, the liquid-phase mass-transfer coefficient $k_{L}$ was determined at transient state through the physical ozone absorption in an acidic aqueous solution containing a radical scavenger (tert-butanol) to prevent ozone decomposition. Then, the gas-phase mass-transfer coefficient $k_{G}$ was determined through the ozone absorption in the fast surface reaction regime, using a solution containing a high sulfite concentration $(0.2 \mathrm{M})$. Finally, the reaction rate constant of the ozone reaction with the resorcinol was determined, considering different correlations developed to calculate 
the ozone Henry's law constant, in the pseudo-first order regime. A sensitivity analysis is provided to assess the robustness of the model and the applicability of the method is thoroughly discussed. 


\section{Material and methods}

\subsection{Reactor}

The $2 \mathrm{~L}$ jacketed gas-liquid contactor (a scheme and a picture of the gas-liquid contactor are presented as Supporting Information, Fig. S1) was designed and manufactured in glass Pyrex by Cloup (France). The $\mathrm{O}_{3} / \mathrm{O}_{2}$ mixture was continuously supplied on the upper part of the reactor whereas the liquid phase $(\mathrm{V}=1.3 \mathrm{~L})$, introduced before the experiments, was in the lower part. These two phases were mechanically agitated by two two-blades turbine (diameter $d_{t}=50 \mathrm{~mm}$ ) at $160 \mathrm{rpm}$. The temperature of the reactor was controlled between 20 and $35^{\circ} \mathrm{C}$ (at $\pm 0.2^{\circ} \mathrm{C}$ ) owing to water circulating in the reactor double-mantle and a thermostatic bath (Lauda Ecoline 003 E100, Germany). The two phases were separated by a flat interface (surface area $=7.72 \times 10^{-3} \mathrm{~m}^{2}$, diameter $=99.12 \mathrm{~mm}$ ). Liquid samples were withdrawn (for $k_{L}$ determination) by a gas-tight syringe (SGE, Australia) through a septum.

\subsection{Experimental set-up}

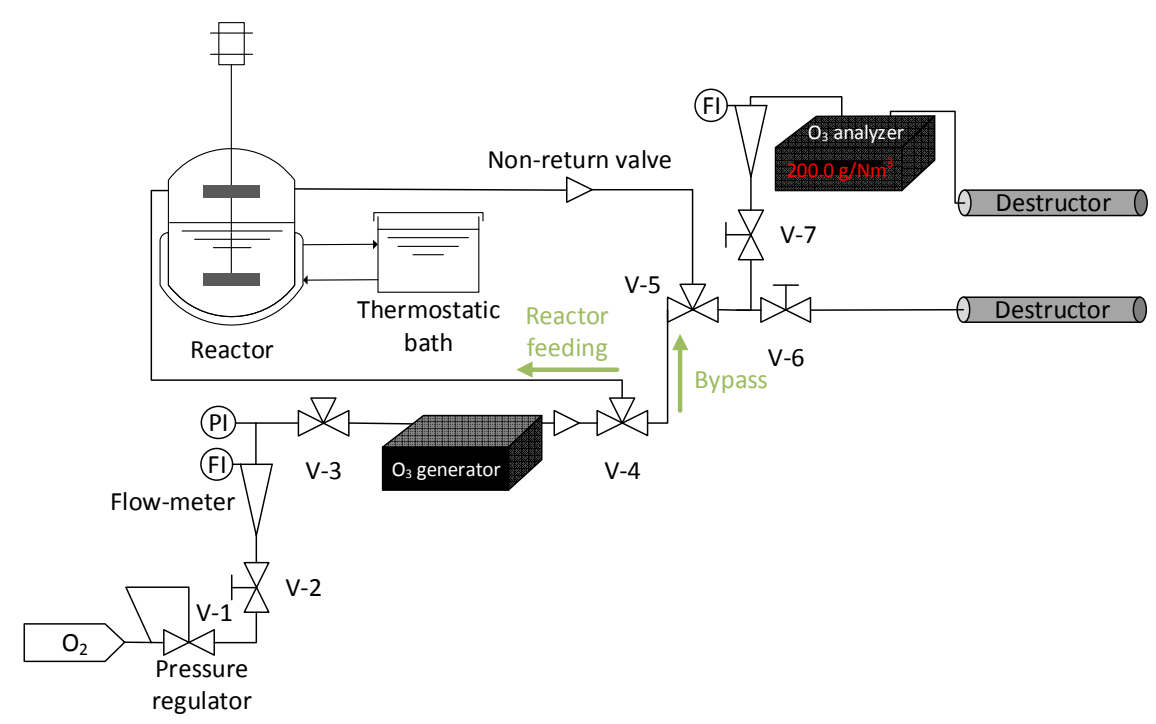

Figure 1: Process Flow Diagram (PFD) of the experimental set-up (A picture is presented as Supporting Information, Fig. S1). 
Ozone was produced from pure oxygen by a generator BMT 803N (Germany, Fig. 1). The oxygen gas flow-rate was controlled through the valve V-2 and measured by a float-type flow-meter (Brooks, ShoRate Model 1355E, USA). A special care was given to control as best as possible the inputs of the model, especially the measured one (gas flow rate, ozone concentration, temperature, etc.). The gas flow-rate read (70 NL h ${ }^{-1}$, where $\mathrm{N}$ accounts for the Standard Temperature and Pressure (STP) conditions, $0^{\circ} \mathrm{C}$ and 1 bar according to the IUPAC) was corrected taking into account the temperature and the pressure at the flow-meter outlet and the ozone content after the ozone generation to determine the real flow-rate at the reactor inlet $\left(F_{G} \approx 68.5 \pm 1.5 \mathrm{NL} \mathrm{h}^{-1}\right.$ according to the Supporting Information S2). Since the pressure drop from the reactor to the destructor was negligible, the pressure inside the reactor was the atmospheric pressure (controlled by a manometer BAMO 95100, France). Owing to the valves V-4 and V5 , the reactor was fed or by-passed by the gas flow which allows to analyze respectively the outlet or the inlet ozone concentration $\left(C_{G, i}\right.$ and $\left.C_{G, o}\right)$. The ozone gas concentration was measured (in $\mathrm{g} \mathrm{Nm}^{-3}$ ) on-line using an analyzer BMT $964 \mathrm{~N}$ having a pressure and temperature compensation (Germany). The valves V6 and V-7 were used to control the relative flow-rate in the ozone analyzer (around $30 \mathrm{NL} \mathrm{h}^{-1}$ ). Ozone was destroyed at the process outlets by two catalytic cartridges provided by BMT (Germany). The tubes, fittings and seals in the process were respectively manufactured in PTFE, stainless steel and Viton ${ }^{\circledR}$ to insure a perfect chemical compatibility with $\mathrm{O}_{3}$. The tube length between the contactor and the ozone analyzer was reduced to the max whereas the flow-rate flowing through the analyzer was maximized to limit as much as possible the dead time and to prevent water condensation. ${ }^{31}$

\subsection{Experimental protocol}

All experiments were performed in Ultra Pure Water (UPW) produced by reverse osmosis (resistivity $<18$ $\mathrm{M} \Omega \mathrm{cm}$ ) by a Purelab system (Elga, France) containing tert-butanol $\left(10^{-3} \mathrm{~mol} \mathrm{~L}^{-1}\right)$ as radical scavenger. First, the gas-liquid reactor was filled with $1.3 \mathrm{~L}$ of the aqueous solution prepared according to the 
different chemical conditions summarized in Table 1. The thermostatic bath was turned-on to set the desired temperature. In the meantime, the oxygen flow-rate was set and the ozone generator and analyzer were warmed-up by by-passing the gas-liquid reactor. When the ozone inlet concentration was constant, the V-4 and V-5 valves were switched to feed the reactor and the time was recorded. The ozone outlet concentration was monitored and $5 \mathrm{~mL}$ samples of the liquid phases were taken regularly for $\mathrm{O}_{3}$ quantification and $\mathrm{pH}$ control if necessary. At the end of the experiment, the reactor was bypassed to reconfirm $C_{G, i}$. The generator was turned off and the solution was drained.

Table 1: Operating conditions. The mass-transfer resistance locations were determined through the calculation of $R_{L}$ according to Eqs 10 or 18.

\begin{tabular}{|c|c|c|c|}
\hline \multicolumn{4}{|c|}{ Conditions : $20^{\circ} \mathrm{C}<T<35^{\circ} \mathrm{C}, \mathrm{N}=160 \mathrm{rpm}, V=1.3 \mathrm{~L}, F_{G} \approx 68.5 \pm 1.5 \mathrm{NL}^{-1}$} \\
\hline Goal & Determination of $k_{L}$ & Determination of $k_{G}$ & $\begin{array}{c}\text { Determination of } k \\
\text { (Ozone/resorcinol reaction } \\
\text { rate constant) }\end{array}$ \\
\hline pH & $2.5 \pm 0.1$ & $10.2 \pm 0.2$ & $2.5 \pm 0.1$ \\
\hline Product added & $\begin{array}{l}\text { Tert-butanol (0.001 M) } \\
\text { Sulfuric acid }\end{array}$ & $\begin{array}{c}\text { Sulfite }(0.2 \mathrm{M}) \\
\text { Tert-butanol }(0.001 \mathrm{M}) \\
\text { Sodium hydroxide }\end{array}$ & $\begin{array}{c}\text { Resorcinol (0.1 M) } \\
\text { Tert-butanol (0.001 M) } \\
\text { Sulfuric acid }\end{array}$ \\
\hline Absorption regime & Physical absorption & $\begin{array}{l}\text { Chemical absorption - } \\
\text { Surface reaction }\end{array}$ & $\begin{array}{c}\text { Chemical absorption - } \\
\text { Pseudo-first order reaction }\end{array}$ \\
\hline $\begin{array}{l}\text { Mass-transfer } \\
\text { resistance location }\end{array}$ & Liquid phase & Gas phase & Both gas and liquid phases \\
\hline
\end{tabular}

\subsection{Analytical methods - Reagents}

The ozone concentration in the liquid phase was analyzed by the Indigo method using an Helios $\gamma$ UV-Vis spectrophotometer (Shimadzu, Japan). ${ }^{32}$ The $\mathrm{pH}$ was measured by a $\mathrm{pH}$ meter Cyberscan 510 (Thermo Scientific Eutech, USA).

Tert-butanol was provided by Sigma Aldrich (USA) with a purity $>99 \%$. Sodium sulfite was provided by Acros Organics (USA). Sodium hydroxide ( $1 \mathrm{~mol} \mathrm{~L}^{-1}$, provided by Merck, Germany) and sulfuric acid ( $0.5 \mathrm{~mol} \mathrm{~L}^{-1}$, provided by Fisher Scientific, USA) were used to set the initial $\mathrm{pH}$. 


\section{Mathematical modeling}

\subsection{General assumptions}

- The gas and the liquid phases were considered as perfectly mixed. ${ }^{33}$ The liquid mixing time (around $4-5 \mathrm{~s}$ according to a pulse injection using a dye) is negligible compared to the experiment duration.

- The process is supposed to be isothermal.

- The molar flux of ozone absorbed is negligible compared to the total gas flow-rate, i.e. the gas flow rate is considered constant throughout the contactor.

\subsection{Ozone absorption in acidic water: liquid-film mass-transfer coefficient $\left(k_{L}\right)$ determination}

$\mathrm{O}_{3}$ was absorbed in ultra-pure water doped with sulfuric acid to set a $\mathrm{pH}$ around 2.5 and in the presence of tert-butanol as a radical scavenger to insure no ozone decomposition in the liquid phase (mass-transfer rate >> ozone decomposition rate). In this case, the mass balance can be written:

$$
\begin{aligned}
& F_{G} C_{G, i}=F_{G} C_{G, o}+V \frac{d C_{L}}{d t} \\
& \Rightarrow F_{G}\left(C_{G, i}-C_{G, o}\right)=V \frac{d C_{L}}{d t}
\end{aligned}
$$

$F_{G}$ is the gas flow rate (read in $\mathrm{NL} \mathrm{h}^{-1}$ and converted in $\mathrm{m}^{3} \mathrm{~s}^{-1}$ ), $C_{G, i}$ and $C_{G, o}$ are respectively the gas concentration at the inlet (subscript i) and the outlet (subscript o) (read in $\mathrm{g} \mathrm{Nm}^{-3}$ and converted in mol $\left.\mathrm{m}^{-3}\right), C_{L}$ is the ozone concentration in the liquid bulk $\left(\mathrm{mol} \mathrm{m} \mathrm{m}^{-3}\right)$ and $V$ is the liquid volume $\left(\mathrm{m}^{3}\right)$. The conversion of the volume expressed at STP $\left(\mathrm{NL}\right.$ or $\mathrm{Nm}^{3}$ ) in $F_{G}$ and $C_{G}$ into the corresponding volume at the working temperature and pressure $\left(\mathrm{L}\right.$ or $\left.\mathrm{m}^{3}\right)$ is detailed in the Supporting Information S2. The mass- 
transfer rate $\left(d J\right.$ in $\left.\mathrm{mol} \mathrm{s}^{-1}\right)$ through the gas-liquid interfacial area $\left(S\right.$ in $\left.\mathrm{m}^{2}\right)$ is calculated according to Eq.

3:

$d J=F_{G}\left(C_{G, i}-C_{G, o}\right)=V \frac{d C_{L}}{d t}=K_{L} S\left(C_{L}^{e q}-C_{L}\right)$

Eq. 3.

$K_{L}$ is the overall liquid-phase mass-transfer coefficient $\left(\mathrm{m} \mathrm{s}^{-1}\right) . C_{L}^{e q}$ is the liquid concentration $\left(\mathrm{mol} \mathrm{m}^{-3}\right)$ at the equilibrium with the gas concentration deduced from the Henry's law. Assuming that the gas and liquid phases are perfectly mixed, $C_{L}^{e q}$ is in equilibrium with $C_{G, o}$ :

$C_{L}^{e q}=\frac{R T C_{G, o}}{H}$

Eq. 4.

$H$ is the ozone Henry's law constant in water $\left(\mathrm{Pa} \mathrm{m}^{3} \mathrm{~mol}^{-1}\right)$. Taking the initial condition $\left(C_{L}=0\right.$ at $\left.\mathrm{t}=0\right)$ into account, Eq. 3 leads to Eqs 5 and 6:

$$
\begin{aligned}
& C_{L}=C_{L}^{e q}\left(1-\exp \left(-\frac{K_{L} S}{V} t\right)\right) \\
& C_{G, o}=C_{G, i}-\frac{K_{L} S C_{L}^{e q}}{F_{G}} \exp \left(-\frac{K_{L} S}{V} t\right)
\end{aligned}
$$

Eq. 5.

Eq. 6.

By including Eq. 4 on Eqs 5 and 6, Eqs 7 and 8 are deduced:

$$
\begin{aligned}
& C_{G, 0}=\frac{C_{G, i}}{1+\frac{K_{L} S R T}{H F_{G}} \exp \left(-\frac{K_{L} S}{V} t\right)} \\
& C_{L}=\frac{C_{G, i}}{\frac{H}{R T}+\frac{K_{L} S}{F_{G}} \exp \left(-\frac{K_{L} S}{V} t\right)}\left(1-\exp \left(-\frac{K_{L} S}{V} t\right)\right)
\end{aligned}
$$

Eq. 8.

$K_{L}$ depends on the gas-phase $\left(k_{G}\right.$ in $\left.\mathrm{m} \mathrm{s}^{-1}\right)$ and liquid-phase $\left(k_{L}\right.$ in $\left.\mathrm{m} \mathrm{s}^{-1}\right)$ mass-transfer coefficients and $H$ through Eq. 9 in physical absorption: ${ }^{34}$ 
$\frac{1}{K_{L}}=\frac{1}{k_{L}}+\frac{R T}{H k_{G}}$

Eq. 9.

Since $\mathrm{O}_{3}$ is poorly soluble in water, the mass-transfer rate in the gas phase is fast compared to the masstransfer rate in the liquid phase $\left(R T k_{L} / H<<k_{G}\right)$ and the relative liquid-side resistance $\left(R_{L}\right)$ tends toward $1:^{35,36}$

$R_{L}=\left(1+\frac{R T k_{L}}{H k_{G}}\right)^{-1}$

Eq. 10.

Therefore, the overall liquid-phase mass-transfer coefficient is equal to the local one $\left(k_{L}=K_{L}\right) .^{3}$ By numerical resolution, trying to minimize the least square Error Function (EF, Eq. 11) between the experimental values of $C_{L}$ and those deduced from Eq. $8, k_{L}$ was determined for each experiment:

$E F=\sum_{i=1}^{n} \frac{1}{n}\left(\frac{C_{L, \exp }^{t_{i}}-C_{L, E q .8}^{t_{i}}}{C_{L, \exp }^{t_{i}}}\right)^{2}$ with $\mathrm{n}$ the number of experimental points

Eq. 11.

\subsection{Ozone absorption in a concentrated sulfite solution: gas-phase mass-transfer coefficient $\left(k_{G}\right)$ determination}

At basic $\mathrm{pH}, \mathrm{O}_{3}$ reacts very quickly with the sulfite anion which is predominant over $\mathrm{HSO}_{3}{ }^{-}$at $\mathrm{pH}>9 .{ }^{37}$ In this case, $K_{L}$ and $R_{L}$ depends on the enhancement (or reaction) factor $(E)$ according to Eq. $12{ }^{34}$ :

$\frac{1}{K_{L}}=\frac{1}{E k_{L}}+\frac{R T}{H k_{G}} \Rightarrow R_{L}=\left(1+\frac{R T E k_{L}}{H k_{G}}\right)^{-1}$

$E$ is the ratio of the absorption rate with and without the reaction for an identical ozone concentration gradient between the interface and the bulk $\left(C_{L}^{*}-C_{L}\right)$. If the enhancement factor is very high to fulfill the condition $R T E k_{L} / H \gg>k_{G}\left(R_{L} \rightarrow 0\right)$, the reaction happens in a plane corresponding to the gas-liquid interface, allowing to concentrate the whole mass-transfer resistance in the gas phase. The ozone 
concentrations at the interface, and obviously in the liquid bulk, are negligible. Therefore, the masstransfer rate is uninfluenced by the chemical reaction rate and the liquid-phase mass-transfer coefficient according to Eq. $13:^{34}$

$F_{G}\left(C_{G, i}-C_{G, o}\right)=k_{G} S C_{G, o}$

$\Rightarrow k_{G}=\frac{F_{G}\left(C_{G, i}-C_{G, o}\right)}{S C_{G, 0}}$

Eq. 13.

A high sulfite concentration was used $(0.2 \mathrm{M})$ to (i) reach high values of $E\left(>10^{4}\right)$ to fulfill the condition $R T E k_{L} / H \gg>k_{G}$ and (ii), to keep the sulfite concentration constant for a sufficient duration to reach a steady state $\left(C_{G, O}\right.$ constant).

The second-order irreversible reaction between $\mathrm{O}_{3}$ and sulfite anion, denoted as a reactant $\mathrm{R}$, is characterized by a reaction rate constant $k\left(\right.$ in $\left.\mathrm{L} \mathrm{mol}^{-1} \mathrm{~s}^{-1}\right)$ :

$\mathrm{O}_{3}+\mathrm{zR} \stackrel{\mathrm{k}}{\longrightarrow}$ products

Eq. 14.

$k$ is equal at $(1.2 \pm 0.1) \times 10^{9} \mathrm{~L} \mathrm{~mol}^{-1} \mathrm{~s}^{-1}$ at $20^{\circ} \mathrm{C}$ for $\mathrm{pH}>9$ and $\mathrm{HSO}_{3}^{-}$can be neglected. ${ }^{37} \mathrm{z}$ is the stoichiometric number equal to 1 for the sulfite oxidation in sulfate. The enhancement factor $E$ was calculated according to the Danckwerts' surface renewal theory through Eq. $15:^{3,38}$

$$
E=-\frac{H a^{2}}{2\left(E_{i}-1\right)}+\sqrt{1+\frac{H a^{4}}{4\left(E_{i}-1\right)^{2}}+\frac{E_{i} H a^{2}}{\left(E_{i}-1\right)^{2}}}
$$

$\mathrm{Ha}$ (Hatta number) is a dimensionless number whose the square quantifies the ratio of the maximal chemical reaction rate and the maximal physical mass-transfer rate:

$$
H a=\sqrt{\frac{k C_{R} D_{L}}{k_{L}^{2}}}
$$


$C_{R}$ is the reactant bulk concentration $\left(\mathrm{mol} \mathrm{L}^{-1}\right.$ ) and $D_{L}\left(D_{R}\right)$ is the ozone (reactant) diffusion coefficient at infinite dilution in water $\left(\mathrm{m}^{2} \mathrm{~s}^{-1}\right) . E_{i}$ is the instantaneous enhancement factor calculated according to the Danckwerts' surface renewal theory through Eq. 17: $:^{3,38}$

$E_{i}=\sqrt{\frac{D_{L}}{D_{R}}}+\frac{C_{R}}{z C_{L}^{*}} \sqrt{\frac{D_{R}}{D_{L}}}$

$C_{L}^{*}$ is the ozone concentration at the interface $\left(\mathrm{mol} \mathrm{L}^{-1}\right)$ deduced from Eq. 18 considering $C_{L}=0$ for $\mathrm{Ha}>$ $5:^{39}$

$C_{L}^{*}=\left(1+\frac{R T E k_{L}}{H k_{G}}\right)^{-1} C_{L}^{e q}=R_{L} C_{L}^{e q}$

Eq. 18.

The dependence of the ozone diffusion coefficient with the temperature was computed using the empirical correlation developed by Johnson and Davis, which is in good agreement with the Wilke-Chang semi-empirical correlation assuming an ozone molar volume of $35.5 \mathrm{~cm}^{3} \mathrm{~mol}^{-1}: 3,40,41$

$D_{L}=1.1 \times 10^{-6} \exp \left(-\frac{1896}{T[K]}\right)$

Eq. 19.

The potential reaction of the sulfite anion with $\mathrm{O}_{2}$ is negligible since the corresponding reaction rate would be lower by 6 order of magnitude to the one of the reaction with $\mathrm{O}_{3} .{ }^{42,43}$ It means that both the oxygen absorption rate (very low solubility in water) and the sulfite consumption by $\mathrm{O}_{2}$ can be ignored.

\subsection{Ozone absorption in a resorcinol solution: determination of the second- order reaction rate constant between $\mathrm{O}_{3}$ and resorcinol}

An excess of resorcinol (0.1 M) was selected. In this case, the stoichiometric number $z$ (defined according to Eq. 14) is equal to $1 / 2$ (two mol of ozone consumed per one mol of resorcinol). ${ }^{19}$ These chemical conditions were selected to insure: 
- A fast reaction in the liquid film located at the gas-liquid interface $(\mathrm{Ha}>5)$. In this case, the ozone transferred is entirely consumed in the liquid film and its concentration in the liquid bulk is zero $\left(C_{L}=0\right)$.

- An excess of resorcinol in the liquid film at the gas-liquid interface compared to $C_{L}^{*}$. Therefore, the resorcinol concentration remains constant and equal to the bulk concentration. This absorption regime corresponds to a pseudo-first order regime particularly convenient for kinetic study by reactive absorption since the mass-transfer rate is uninfluenced by $k_{L}$ and $D_{R}$ which are rather inaccurate. ${ }^{15,20}$ The Hatta numbers obtained were rather large (650-800). In this case, the considered mass-transfer theory (double-film or surface renewal theories) has no influence and the enhancement factor is equal to the Hatta number :

$E=H a$ Eq. 20.

Therefore Eqs 3, 4, 12 and 16 lead to:

$F_{G}\left(C_{G, i}-C_{G, o}\right)=\frac{1}{\frac{1}{\sqrt{k C_{R} D_{L}}}+\frac{R T}{H k_{G}}} S \frac{R T C_{G, o}}{H}$ Eq. 21.

Consequently:

$k=\frac{1}{C_{R} D_{L}}\left(\frac{H}{R T}\right)^{2}\left(\frac{S C_{G, o}}{F_{G}\left(C_{G, i}-C_{G, o}\right)}-\frac{1}{k_{G}}\right)^{-2}$

Eq. 22.

- to insure that the aforementioned assumption lasts long enough even considering the resorcinol consumption by the reaction. Therefore, $C_{R}$ and $C_{G, O}$ remained constant over time for a sufficient duration to reach a steady-state. The by-products concentration is negligible. $k$, the reaction rate constants of the resorcinol reaction with ozone, can be simply deduced from Eq. 22 regardless of time $t$. According to the balanced equation 14, the reaction rate constant referred to the ozone consumption rate. 


\section{Results and discussion}

\subsection{Determination of the liquid-film mass-transfer coefficient $\left(k_{L}\right)$}

\subsubsection{Experimental results}
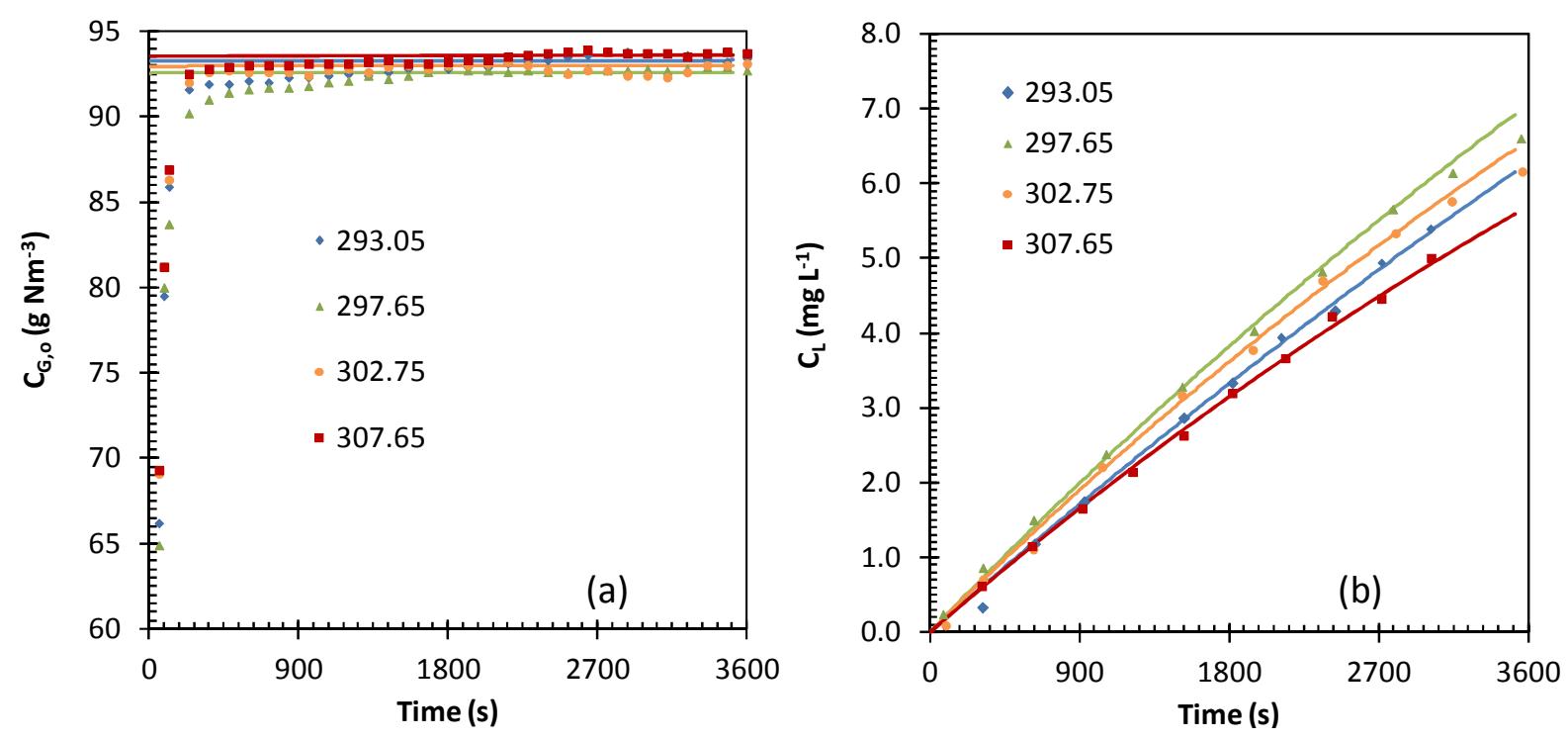

Fig. 2 : Time course of the ozone gas (a) and liquid (b) concentrations. The straight lines correspond to the model (Eqs 7 and 8) using $k_{L}$ reported in Table 2.

The determination of $k_{L}$ was based on the physical ozone absorption in water at transient state. Tert-butanol was added as radical scavenger and an acidic $\mathrm{pH}$ was set to prevent $\mathrm{O}_{3}$ decomposition. Owing to a low absorption rate, $C_{G, o}$ is not significantly different to $C_{G, i}$ (Fig. 2a). The duration necessary for the experimental values to reach the theoretical values is an indication of the dead time in the tube. After the first experiment (around 298K corresponding to the green triangle symbols), the tubes length and the gas flow rate in the analyzer were respectively decreased and increased to shorten this dead time to approximately $5 \mathrm{~min}$. In parallel, the liquid ozone concentration gradually increased (Fig. $2 \mathrm{~b}$ ). The experiments were stopped after $1 \mathrm{~h}$ corresponding to dissolved ozone concentrations in the range 5-7 ppm, far from the ozone concentrations that can be reached at the equilibrium (15 to $30 \mathrm{ppm}$ depending 
on the temperature). The concentration at $293 \mathrm{~K}$ remains lower than at 298 and $303 \mathrm{~K}$ since $C_{G, i}$ was slightly higher. After each experiment, $100 \mathrm{~mL}$ of the liquid phase was withdrawn and injected in a 100 $\mathrm{mL}$ gas-tight syringe and placed in a thermostatic chamber. ${ }^{44}$ The absence of ozone decomposition was confirmed by a constant ozone concentration after one hour.

\subsection{2. $k_{L}$ calculation}

According to Eq. 8, the mass-transfer rate in physical absorption is sensitive to the value of the ozone Henry's law constant whose the value is controversial in the specialized literature. ${ }^{29,45}$ The International Ozone Association recommends to calculate $H$ as a function of the temperature between 0 and $60^{\circ} \mathrm{C}$ through Eq. $23:^{45}$

$H=1.599 \exp \left(0.0473 \times T\left[{ }^{\circ} \mathrm{C}\right]\right) \times R \times T[K]$

Eq. 23.

However, this equation seems to overestimate $\mathrm{H}$, especially at temperature higher than $25^{\circ} \mathrm{C} .{ }^{29,46}$ The equation derived from Perry (1973), and reported by Mandel (2010), is quite often used for engineering purpose:

$(\log H) /(R \times T[K])=6.20-\frac{1687}{T[K]}$ for $288 \mathrm{~K}<\mathrm{T} \leq 303 \mathrm{~K}$
$(\log H) /(R \times T[K])=3.25-\frac{1687}{T[K]}$ for $278 \mathrm{~K} \leq \mathrm{T} \leq 288 \mathrm{~K}$

Eq. 24.

Furthermore, two new equations (Eqs 25 and 26) have been recently introduced by Mizuno and Tsuno (2010) and Ferre-Aracil et al. (2015): ${ }^{46,47}$

$H=\left(-0.0067 \times T\left[{ }^{\circ} \mathrm{C}\right]+0.4474\right)^{-1} \times R \times T[K]$ proposed by Mizuno and Tsuno Eq. 25.

$H=1.797 \exp \left(0.0277 \times T\left[{ }^{\circ} \mathrm{C}\right]\right) \times R \times T[K]$ proposed by Ferre-Aracil et al. Eq. 26.

The agreement between the correlations of Mizuno and Tsuno (2010) and Ferre-Aracil et al. (2015) is surprisingly excellent for $\mathrm{T}>20^{\circ} \mathrm{C}$ (a maximal relative difference of $4 \%$ exists at $20^{\circ} \mathrm{C}$ ) even if different 
experimental procedures were adopted (Fig S2 in Supporting Information). Owing to the high disagreement of Eq. 23, only the equations 24-26 were considered to determine the values of $k_{L}$ according to Eq. 8. The values of these three models provide an acceptable agreement (Table 2). The relative gap between the values obtained with the Perry's correlation and the correlations of Ferre-Aracil et al. (2015) and Mizuno-Tsuno (2010) is always lower than $15 \%$.

Table 2: Determination of $k_{L}$ with the temperature for different correlations used to determine $\boldsymbol{H}$.

\begin{tabular}{|c|c|c|c|c|c|}
\hline & Perry & Ferre-Aracil et al. & Mizuno and Tsuno & \multicolumn{2}{|c|}{ Average } \\
\hline$T(\mathrm{~K})$ & $10^{5} \times k_{L}\left(\mathrm{~m} \mathrm{~s}^{-1}\right)$ & $10^{5} \times k_{L}\left(\mathrm{~m} \mathrm{~s}^{-1}\right)$ & $10^{5} \times k_{L}\left(\mathrm{~m} \mathrm{~s}^{-1}\right)$ & $10^{5} \times k_{L}\left(\mathrm{~m} \mathrm{~s}^{-1}\right)$ & $R_{L}(\%)$ \\
\hline 293.05 & 1.05 & 1.19 & 1.22 & $1.15 \pm 0.07$ & 99.90 \\
\hline 297.65 & 1.54 & 1.61 & 1.64 & $1.59 \pm 0.03$ & 99.90 \\
\hline 302.75 & 1.85 & 1.77 & 1.74 & $1.78 \pm 0.05$ & 99.91 \\
\hline 307.65 & 1.99 & 1.76 & 1.74 & $1.83 \pm 0.11$ & 99.92 \\
\hline
\end{tabular}

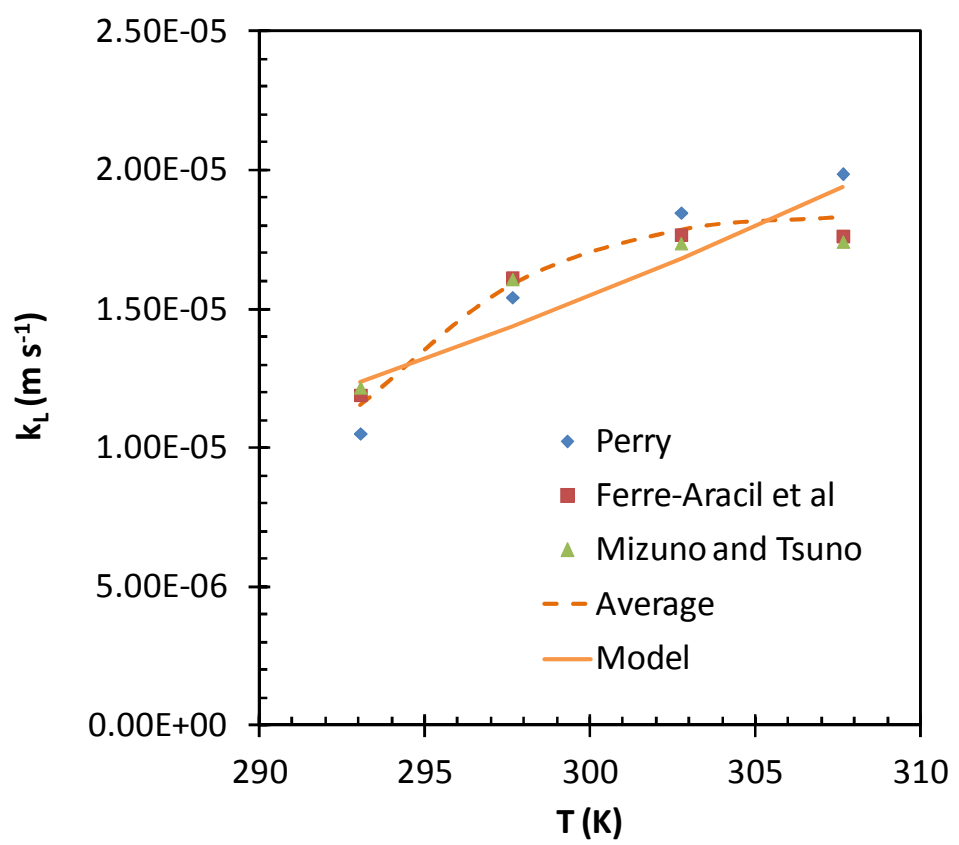

Fig. 3 : Evolution of $k_{L}$ vs. the temperature considering different correlations used to calculate the ozone Henry's law constant. The model is deduced from Eq. 27 with $C_{1}=0.542, C_{2}=0.11$ and $C_{3}=0.66$. The order of magnitude of $k_{L}\left(10^{-5} \mathrm{~m} \mathrm{~s}^{-1}\right)$ is lower than the one encountered in traditional gas-liquid contactors $\left(10^{-4} \mathrm{~m} \mathrm{~s}^{-1}\right)$ but consistent with the values found by Versteeg et al. in a stirred-cell reactor at 
similar Reynolds number. ${ }^{25,}{ }^{26}$ This low order of magnitude of $k_{L}$ is expected considering that there is no mixing of both phases which would then induce a larger diffusion path. ${ }^{34}$ According to the Higbie penetration theory, the renewal time would range between 7.5 and 20 s. $k_{L}$ increases with temperature (Fig. 3) owing to both a diffusivity and a liquid viscosity increasing (i.e. Reynolds and Schmidt numbers (Re and Sc) increasing). The average values of $k_{L}$ were correlated to the viscosity and the diffusivity owing to the following dimensionless equation: ${ }^{16,26}$

$$
S h=C_{1} S C^{C_{2}} \operatorname{Re}^{C_{3}} \quad \text { Eq. } 27 .
$$

Sh corresponds to the Sherwood number. A better agreement was found with the correlation of Kucka et al. than with the correlation of Versteeg et al. ${ }^{16}$ Using their values of $C_{2}$ and $C_{3}$ (respectively 0.11 and 0.66), a value of $C_{1}$ equal to $0.542,23 \%$ lower than the one found by Kucka et al., was determined by numerical resolution (the model is represented in Fig. 3). The relative error between the model and the average values of $k_{L}$ varies from $2.5 \%$ to $15 \%$, which is acceptable when determining mass-transfer coefficients.

\subsubsection{Assumption verification}

To validate the assumption of a negligible resistance in the gas phase, the relative liquid side resistance was evaluated according to Eq. 12 . Whatever the temperature, $R_{L}$ was higher than $99.9 \%$ (Table 2 ), which validates the assumption.

\subsection{Determination of the gas-film mass-transfer coefficient $\left(k_{G}\right)$}

\subsubsection{Experimental results $-k_{G}$ calculation}

The determination of $k_{G}$ was based on the ozone absorption in the surface reaction regime. The initial sulfite concentration $\left(C_{R}=0.2 \mathrm{~mol} \mathrm{~L}^{-1}\right)$ was selected to insure that this assumption lasted long enough owing to a negligible sulfite consumption. Consequently, after a few minutes corresponding to 
the dead time between the contactor and the analyzer, the outlet ozone concentration reached a plateau. Depending on the temperature, the ratio $C_{G, 0} / C_{G, i}$ was in the range $36-41 \%$ (Table 3). Ozone concentration in the liquid phase remained immeasurable showing that $\mathrm{O}_{3}$ was entirely consumed in the liquid film and does not diffuse in the liquid bulk. $C_{G, O}$ at the plateau was considered for the calculation of the $k_{G}$ values according to Eq. 13 (Table 3). The order of magnitude of $k_{G}\left(10^{-3} \mathrm{~m} \mathrm{~s}^{-1}\right)$ is lower than the one encountered in traditional gas-liquid contactors $\left(10^{-2}\right.$ to $\left.10^{-1} \mathrm{~m} \mathrm{~s}^{-1}\right)$ but consistent with the order of magnitude found by Vertseeg et al. in a stirred-cell reactor for similar operating conditions. ${ }^{26} k_{G}$ increased by $20 \%$ from 20 to $30^{\circ} \mathrm{C}$ and remains approximately constant up to $35^{\circ} \mathrm{C}$. According to a dimensionless equation similar to Eq. 27 developed by Versteeg et al., $k_{G}$ should be proportional to the square root of the gas phase diffusion coefficient, in agreement with the Higbie's penetration theory and the Danckwerts' surface renewal theory. ${ }^{26} k_{G}$ should be also proportional to the gas viscosity to the power of $-0.13 .{ }^{26}$ Since both the gas viscosity and ozone diffusion coefficient (computed according to the correlation proposed by Massmann et al. ${ }^{48}$ for $\mathrm{O}_{3}$ ) slightly increase with the temperature (by less than $3 \%$ for $D_{G}$ and $1 \%$ for $\mu_{G}$ between 20 and $35^{\circ} \mathrm{C}$ ), the increasing of $k_{G}$ with the temperature should be less sharp than the experimental results. Regarding the high experimental uncertainties which lie to masstransfer coefficient determination, the experimental results remain fully acceptable.

Table 3: Determination of $k_{G}$ with the temperature.

\begin{tabular}{cccccc}
\hline $\mathrm{T}\left({ }^{\circ} \mathrm{C}\right)$ & $\mathbf{2 0}$ & $\mathbf{2 5}$ & $\mathbf{3 0}$ & $\mathbf{3 5}$ \\
\hline $\boldsymbol{C}_{G, o} / C_{G, i}$ & 0.41 & 0.38 & 0.36 & 0.36 \\
$\boldsymbol{C}_{G, o}\left(\mathrm{~g} \mathrm{Nm}^{-3}\right)$ & 9.9 & 8.5 & 7.9 & 8.0 \\
$10^{-3} \boldsymbol{k}_{G}\left(\mathrm{~m} \mathrm{~s}^{-1}\right)$ & 3.95 & 4.40 & 4.86 & 4.80 \\
$\left(\boldsymbol{R T E k _ { L }} / \mathrm{H}\right) / \boldsymbol{k}_{G}$ at steady state & 51 & 58 & 30 & 20 \\
$\boldsymbol{R}_{L}{ }^{\mathrm{a}}(\%)$ & 1.9 & 1.7 & 3.2 & 4.7 \\
$\Delta t(\mathrm{~min})$ & 35 & 36 & 35 & 35 \\
\hline
\end{tabular}

${ }^{a} R_{L}$ was overstimated at 25,30 and $35^{\circ} \mathrm{C}$ since the reaction rate constant of the sulfite oxidation was taken at $20^{\circ} \mathrm{C}$. 


\subsubsection{Assumptions verification}

Two conditions must be fulfilled: (i) The relative resistance in the liquid phase $R_{L}$ must tend towards 0 which implies very large values of the enhancement factor $E$ and (ii) the sulfite concentration must remain constant for a sufficient time.

$R_{L}$ was calculated according to Eqs. $10,15-18$ and was always lower than $5 \%$ (Table 3 ). It is noteworthy that the real values of $R_{L}$ would be lower at 25,30 and $35^{\circ} \mathrm{C}$ since the value of $k$ was unknown at these temperatures and underestimated using the value at $20^{\circ} \mathrm{C}$ instead.

The time $(\Delta t)$ necessary to observe a variation of the initial sulfite concentration of only $5 \%$ was also calculated according to Eq. 28 deduced from the mass-balance:

$\Delta t=0.05 \frac{C_{R}}{z} V \frac{M_{O_{3}}}{F_{G}\left(C_{G, i}-C_{G, o}\right)}$ with $F_{G}\left(C_{G, i}-C_{G, o}\right)$ calculated in $\mathrm{g} \mathrm{s}^{-1}$

Eq. 28.

This duration was always higher than $30 \mathrm{~min}$, which was sufficient to measure the outlet ozone concentration at steady state.

\subsection{Determination of the resorcinol reaction with $0_{3}$ rate constant}

\subsubsection{Experimental results - $k$ calculation}

Table 4: Values of the reaction rate constant $k\left(10^{5} \mathrm{~L} \mathrm{~mol}^{1} \mathrm{~s}^{-1}\right)$ (associated to the balance equation $\mathrm{O}_{3}+1 / 2$ resorcinol $\rightarrow$ products) considering different correlations to calculate the ozone Henry's law constant.

\begin{tabular}{|c|c|c|c|}
\hline \multirow{2}{*}{ Temperature $\left({ }^{\circ} \mathrm{C}\right)$} & \multicolumn{3}{|c|}{ Correlation used to determine the Henry's law constant } \\
\cline { 2 - 4 } & Perry $^{29}$ & Ferre-Aracil et al. ${ }^{46}$ & Mizuno-Tsuno $^{47}$ \\
\hline 20 & $3.57 \pm 0.20$ & $4.50 \pm 0.25$ & $4.68 \pm 0.26$ \\
\hline 25 & $5.39 \pm 0.20$ & $5.73 \pm 0.21$ & $5.67 \pm 0.21$ \\
\hline 30 & $6.89 \pm 0.59$ & $6.30 \pm 0.53$ & $6.10 \pm 0.52$ \\
\hline 35 & $12.2 \pm 0.8$ & $9.67 \pm 0.60$ & $9.50 \pm 0.59$ \\
\hline
\end{tabular}


As expected, after a few minutes corresponding to the dead time, the ozone outlet concentration reached a constant value for a sufficient duration (steady state). From Eq. 22 and the value of $C_{G, O}$ at steady state, the reaction rate constant $k$ was deduced at each temperature (the experiments were repeated 4 times with a relative standard deviation in the range $4-9 \%$ at each temperature). Owing to a lower mass-transfer enhancement with resorcinol $(650<E<800)$ than with sulfite $\left(E>10^{4}\right)$, the ratio $C_{G, 0} / C_{g, i}$ was higher (58 to $62 \%$ ) but consistent to determine $k$ with a good accuracy. The values of $k$ depends significantly on the selected model used to determine the ozone Henry's law constant since the relative gap between the values deduced from the Ferre-Aracil et al. and Perry's correlations varies from $6 \%$ at $25^{\circ} \mathrm{C}$ up to $23 \%$ at 20 and $35^{\circ} \mathrm{C}$ (Table 4 and Fig. 4). The relative difference between the FerreAracil et al. and Mizuno-Tsuno correlations is not significant (between 1 and $4 \%$ from 20 to $35^{\circ} \mathrm{C}$ ), therefore only the results gathered with the correlation reported by Ferre-Aracil et al. were considered. The value determined at $20^{\circ} \mathrm{C}$ is in agreement with the value reported by Hoigné and Bader $\left(>3 \times 10^{5} \mathrm{~L}\right.$ $\mathrm{mol}^{-1} \mathrm{~s}^{-1}$ ) but which has been measured during only one experiment using an homogeneous system. ${ }^{49}$ The order of magnitude at $20^{\circ} \mathrm{C}$ is also coherent with the values found at acidic pH by Sotelo et al. by reactive absorption $\left(1.01 \times 10^{5} \mathrm{~L} \mathrm{~mol}^{-1} \mathrm{~s}^{-1}\right)$ and by Gurol and Nekouainini using the competitive method in an heterogeneous reactor $\left(0.91 \times 10^{5} \mathrm{~L} \mathrm{~mol}^{-1} \mathrm{~s}^{-1}\right.$ according to the calculation of Sotelo et al. (1991)). ${ }^{20,50}$ The same balanced equation than Eq. 14 was considered by Sotelo et al. (1991), which allows the direct comparison of the values of the reaction rate constants $k$. In the experimental conditions of Gurol and Nekouinaini (1984), the reaction rate constant was extrapolated from the phenol reaction rate constant $\left(1.3 \times 10^{3} \pm 0.3 \times 10^{3} \mathrm{~L} \mathrm{~mol}^{-1} \mathrm{~s}^{-1}{ }^{49}\right)$. Nonetheless, the stoichiometries of both ozone reactions with phenol and resorcinol were not considered in the calculation, which makes the comparison of the values of the reaction rate constants not pertinent. In the experimental conditions of Sotelo et al. (1991), the interfacial area was not controlled and was measured through the oxygen absorption in the pseudo-first order regime in an aqueous solution of cuprous chloride. This determination is affected by rather high 
experimental uncertainties. In the experimental conditions of this study, several variables can affect the accuracy (section 4.4). All these reasons justify the discrepancy with the value of Sotelo et al. (1991).

The temperature dependence of $k$ was satisfactorily modeled using the Arrhenius equation after linearization ( $R^{2}=97.4 \%$ (Perry) and $R^{2}=92.7 \%$ (Ferre-Aracil et al.), Fig. 5):

$k\left[\operatorname{Lmol}^{-1} \mathrm{~s}^{-1}\right]=1.02 \times 10^{16} \exp \left(-\frac{58.7 \times 10^{3}}{R T[K]}\right)$ with $H$ estimated by the Perry's correlation $\quad$ Eq. 29. $k\left[\operatorname{Lmol}^{-1} \mathrm{~S}^{-1}\right]=1.02 \times 10^{12} \exp \left(-\frac{35.7 \times 10^{3}}{R T[K]}\right)$ with $H$ estimated by the correlation of Ferre-Aracil et al. $\quad$ Eq. 30.

The values of the activation energies are particularly sensitive to the considered Henry's law constant correlation used with a relative difference of $40 \%\left(35.7\right.$ and $\left.58.7 \mathrm{~kJ} \mathrm{~mol}^{-1}\right)$. According to the reaction rate constants determined between 1 and $20^{\circ} \mathrm{C}$, the data of Sotelo et al. (1991) were extrapolated between 20 and $35^{\circ} \mathrm{C}$ using the Arrhenius equation with an activation energy of $35.0 \mathrm{~kJ} \mathrm{~mol}^{-1}$, close to the one found considering the correlation of Ferre-Aracil et al. (Fig. 4). Sotelo et al. used their own correlation to calculate the Henry's law constant. ${ }^{51}$ This correlation over-predicts $H$ compared to the correlations considered in this study, but the temperature dependence is almost the same than the correlation of Ferre-Aracil et al. (Fig. S.2). Therefore, the dependence of the reaction rate constant with the temperature between this study and the one of Sotelo et al. is identical. Nonetheless, it cannot be concluded that the value of the activation energy is around $35 \mathrm{~kJ} \mathrm{~mol}^{-1}$ since the true variation of $H$ with the temperature is still unknown. The difference between both studies is certainly due to one or several systematic errors.

Eqs. 29 and 30 were used to extrapolate the reaction rate constant $k$ between 1 and $20^{\circ} \mathrm{C}$ (Fig. 4 ). A better agreement with the values of Sotelo et al. is found considering the Perry's correlation ( $15 \%$ and $12 \%$ of relative difference at $10^{\circ} \mathrm{C}$ and $1^{\circ} \mathrm{C}$ ). Nonetheless, the values of Sotelo et al. (1991) were also dependent on the Henry's law constant used, therefore this comparison should be considered carefully. 
Thus, owing to their novelty, pertinent experimental planning and good respective agreement, there is a high temptation to consider the Ferre-Aracil et al. and Mizuno-Tsuno correlations as the most accurate but further studies would be necessary to definitely confirm it. ${ }^{20}$ Finally, these observations highlight an inherent drawback of the reactive absorption method which is sensitive to several physicochemical properties of the reactants (solubility, diffusivity, gas and/or liquid phase mass-transfer coefficients, etc.), which are in the case of $\mathrm{O}_{3}$ rather uncertain.

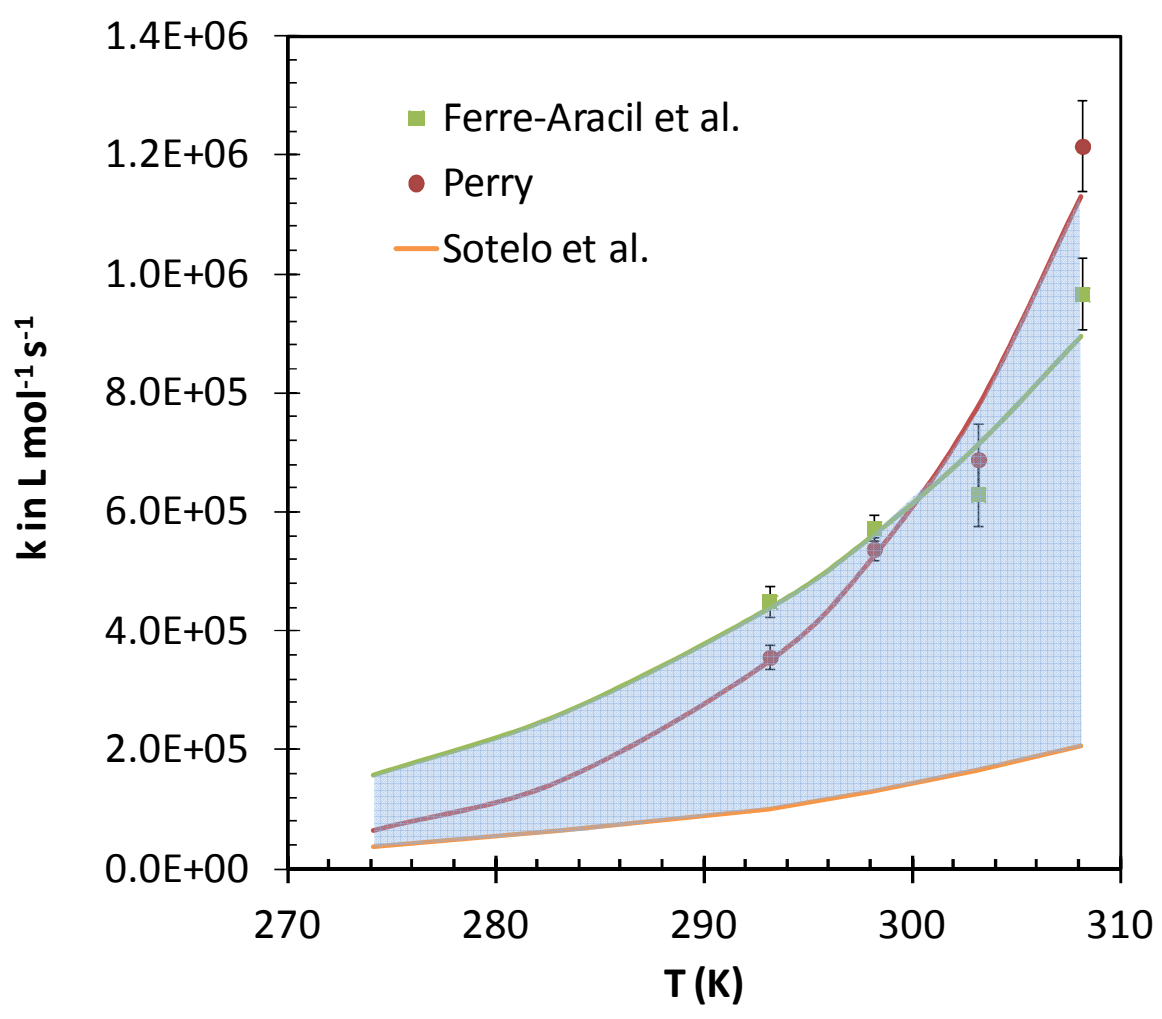

Fig. 4 : Evolution of $k$ vs the temperature considering the Ferre-Aracil et al. and Perry's correlations to calculate the ozone Henry's law constant. The values of Sotelo et al. were extrapolated between 20 and $35^{\circ} \mathrm{C}$ from the data at 1,10 and $20^{\circ} \mathrm{C}$ using the Arrhenius law (Fig. 5). ${ }^{20}$ The error bars correspond to the standard deviation of the experimental points. 


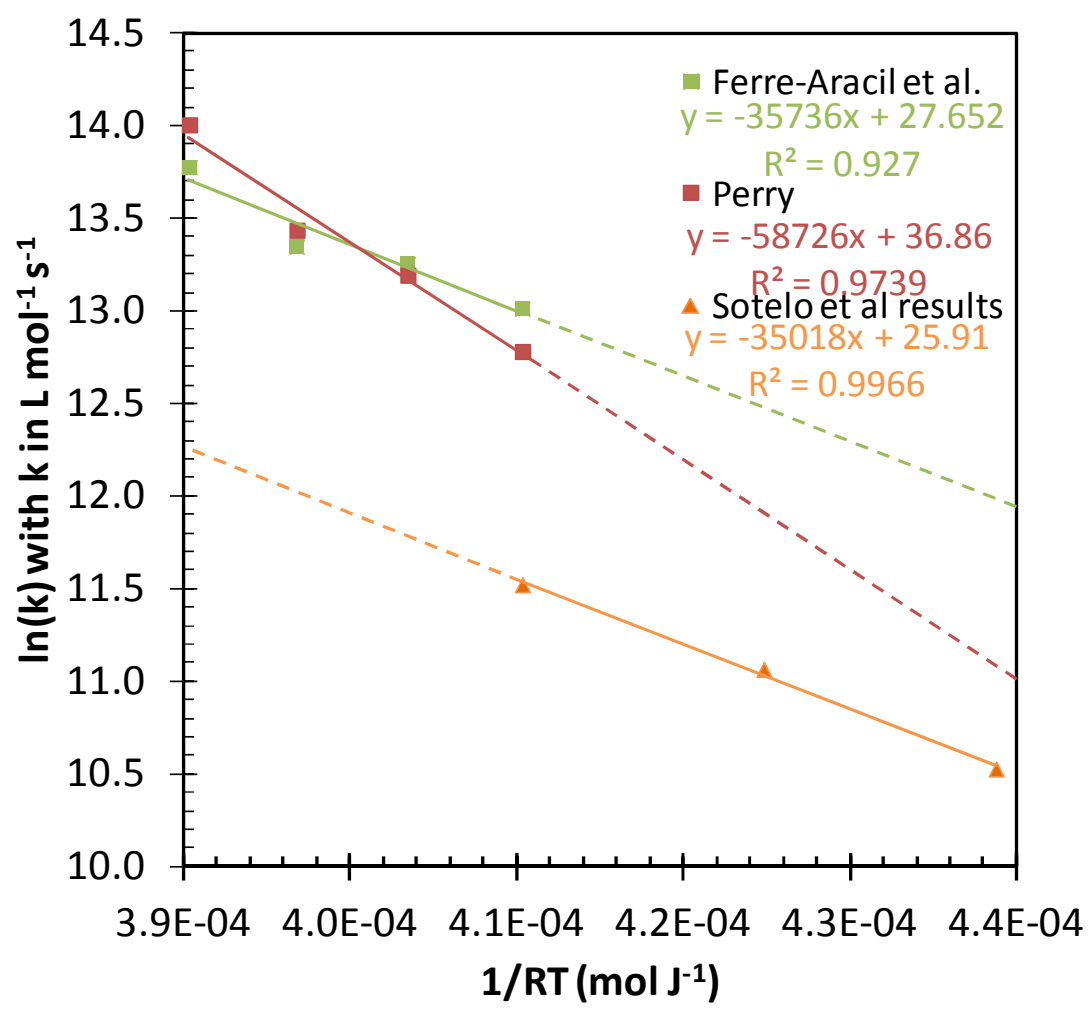

Fig. 5 : Plot of $\ln (k)$ vs. 1/RT (Arrhenius law linearization) considering the Ferre-Aracil et al. and Perry's correlations to calculate the ozone Henry's law constant and with the values of $k$ determined by Sotelo et al. ${ }^{20}$

\subsubsection{Assumptions verification}

Two conditions were fulfilled: (i) The enhancement factor, to be approximated to the Hatta number (Eq. 20), was always lower than half the value of the instantaneous enhancement factor $E_{i}$ (calculated with the Eqs. 17 and 18); (ii) the resorcinol concentration remained constant for a sufficient duration. Indeed, according to Eq. 28, the time necessary to observe a decreasing of the initial resorcinol concentration of $5 \%$ was around $15 \mathrm{~min}$, which was enough to measure $C_{G, 0}$ with a good agreement at the steady state.

It is noteworthy that such enhancement factors $(650<E<800)$ concentrate a significant part of the mass-transfer resistance in the gas phase, with $R_{L}$ in the range $58-63 \%$. Therefore, even if the resistance in the liquid phase remains higher, the determination of $k$ is sensitive to the values of $k_{G}$ determined 
previously (4.2). Consequently, the relative influence of all the variables on the value of the reaction rate constant should be addressed by a sensitivity analysis.

\subsection{Sensitivity analysis}

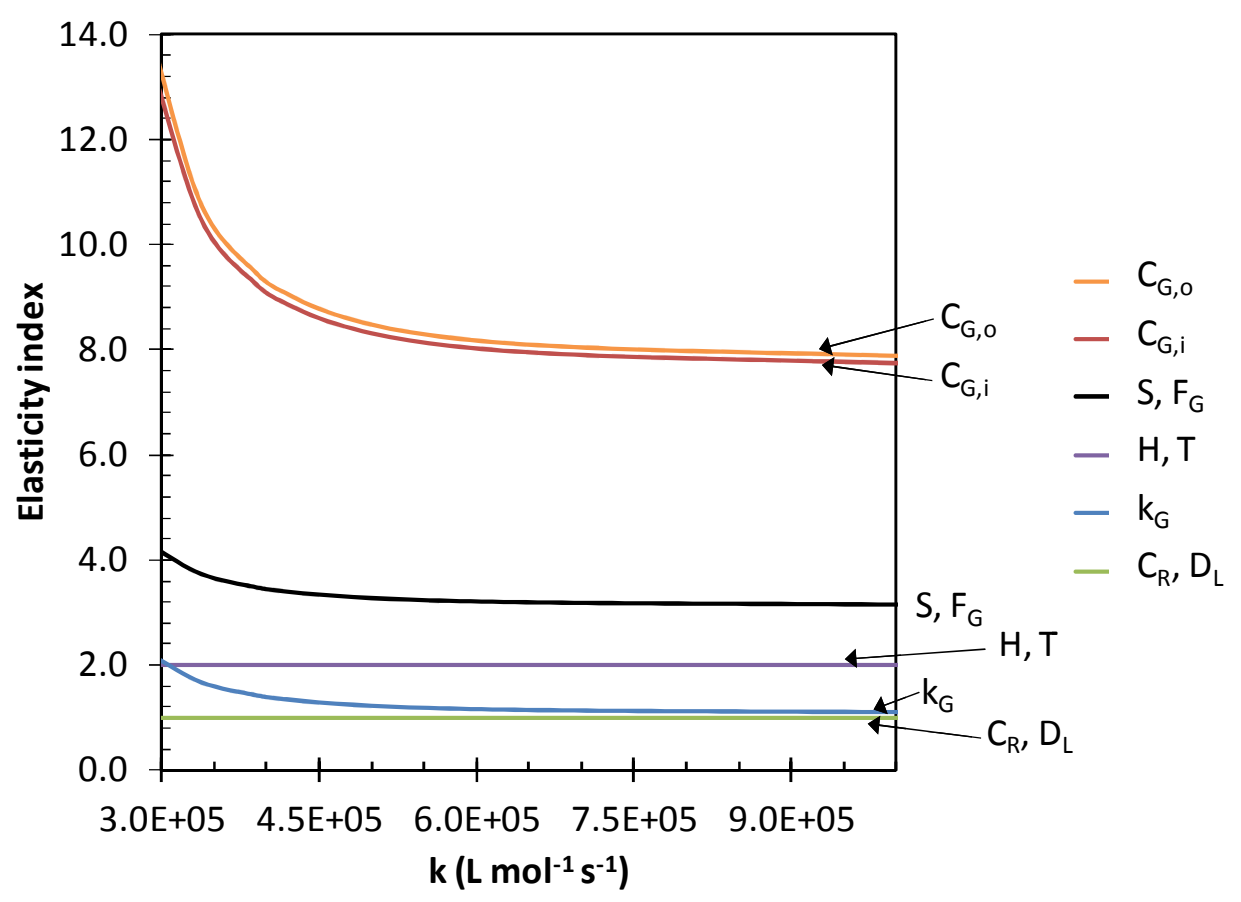

Fig. 6 : Plot of the elasticity index of the model inputs vs. the value of the output (reaction rate constant $k$ ).

To assess the influence of the different inputs $(I)$ on the output $(O$, here $k$ the second order reaction rate constant) and to gain information on the model, a simple and local sensitivity analysis method based on the elasticity index $(E I)$ calculation has been achieved: ${ }^{15,42}$

$$
E I_{l}^{O}=\left|\frac{I}{O}\left(\frac{\partial O}{\partial I}\right)\right|
$$

The sensitivity of the output to an input is shortened when El tends toward 0.Two main classes of inputs can be distinguished: the inputs corresponding to physico-chemical properties $\left(H, D_{L}\right)$ and those corresponding to the set experimental conditions $\left(C_{R}, S, T, F_{G}, C_{G, i}\right)$ and to $C_{G, o} . k_{G}$ can be classified 
separately, corresponding to a parameter evaluated previously in the same operating conditions (stirrer speed, turbines positions, temperatures).

The elasticity index was evaluated for $k$ values ranging between $3 \times 10^{5}\left(\approx 20^{\circ} \mathrm{C}\right)$ and $10^{6}\left(\approx 35^{\circ} \mathrm{C}\right) \mathrm{L} \mathrm{mol}^{-1} \mathrm{~s}^{-1}$ (Fig. 6). This sensitivity analysis emphasizes a high sensitivity of the output $k$ to all the inputs, since the elasticity index varies from 1 up to 10. The most significant inputs affecting the model are two measured data, the inlet and outlet ozone concentrations, especially for low values of $k$. For example, for $k$ around $3.5 \times 10^{5} \mathrm{~L} \mathrm{~mol}^{-1} \mathrm{~s}^{-1}$ (corresponding to $\mathrm{T} \approx 20^{\circ} \mathrm{C}$ with the Perry's correlation), the elasticity index is approximately equal to 10 . It means that an error on $C_{G, O}$ or $C_{G, i}$ of $10 \%$ leads to an error on $k$ of $100 \%$. However, these inputs were measured by an on-line ozone analyzer approved for its high accuracy claimed under $0.5 \%$ according to the supplier (BMT, Germany). Nonetheless, since the ozone production by the ozone generator was not perfectly stable, both the inlet and outlet concentrations varies slightly during the steady state (average values were considered) which can affects the calculation significantly. With a lower extent, the interface area $(S)$ and gas flow rate $\left(F_{G}\right)$ influence also significantly the output. The interfacial area was rather well-known (measured with a sliding caliper). However the gas flow rate was measured with a float-type flow-meter having an accuracy of $5 \%$. The rather high relative gap between the values of $k$ determined with different correlations to calculate $H$ is confirmed by a sensitivity index of 2. For example, the Ferre-Aracil et al. and Perry's correlations provide a relative gap of $11 \%$ for $H$ at $20^{\circ} \mathrm{C}$, the relative gap observed for the $k$ values determined with these correlations at $20^{\circ} \mathrm{C}$ is around $22 \%$. The less significant inputs are $k_{G}, C_{R}$ and $D_{L}$. On the one hand, $C_{R}$ was set with a good precision. On the other hand, $D_{L}$ is still subject to controversy for ozone. Only two studies (Johnson and Davies, considered in this study, and Matrozov et al.) were carried out to measure it using similar experimental procedures, but the authors found values with a relative difference of $30 \%$ at $20^{\circ} \mathrm{C}^{3,40}$ Finally, $k_{G}$ was measured previously and is affected by experimental uncertainties. However, the sharp dependence of $k_{G}$ to the temperature (4.2.1) seems to confirm a significant inaccuracy since according to 
the results of Versteeg et al., $k_{G}$ should remain almost constant between 20 and $35^{\circ} \mathrm{C}^{26}$ The determination of $k$ remains insensitive to $k_{L}$ and the reactant diffusion coefficient as long as the recommended pseudo-first order regime is applied. This sensitivity analysis confirms the sensitivity of $k$ to the different output. Nonetheless, the reactive absorption method is used to determined large kinetic constants whose a perfect accuracy is unexpected for practical applications.

\subsection{Discussion on the applicability of the method}

The method is based on the ozone absorption in the pseudo-first order regime in a stirred-cell reactor operated semi-continuously. In a given stirred-cell reactor at a given stirring speed, the inputs which can be potentially modified to optimize the experimental management are the reactant concentration $\left(C_{R}\right)$, the inlet ozone concentration $\left(C_{G, i}\right.$, affecting the outlet ozone concentration $\left.C_{G, o}\right)$, the gas flow rate $\left(F_{G}\right)$ and the liquid volume $(V)$. For neutral reactants, an acidic $\mathrm{pH}$ and the addition of tert-butanol are recommended to avoid the ozone decomposition. For acid or basic reactants, the pH must be set in agreement with the reactant acidity dissociation constant and the absence of ozone decomposition must be controlled (a higher tert-butanol concentration should be applied). $C_{G, i}$ can be varied under a wide range (from a few $\mathrm{g} \mathrm{Nm}^{-3}$ to $150-200 \mathrm{~g} \mathrm{Nm}^{-3}$, depending on the ozone generator, gas flow rate and oxygen content). On the contrary, the liquid volume $(0.2<\mathrm{V}<2 \mathrm{~L})$ and the gas flow rate $\left(20<\mathrm{F}_{\mathrm{G}}<200 \mathrm{~L}\right.$ $\mathrm{h}^{-1}$ ) have a limited range of applicability to match the lab-scale constraints. Furthermore, the gas flow rate must be set in order to limit the analytical dead time (which depends on both the reactor headspace volume and tubes volume) and maximize the ozone concentration for more accuracy. Therefore, it is recommended to set $V$ and $F_{G}$ at the beginning of the study to avoid a reevaluation of the mass-transfer characteristics each time an operating condition is changed. A "high" reactant concentration $\left(C_{R}\right)$ in solution is used to neglect its consumption and avoid the by-products accumulation. First, the term

"high" needs to be quantified. Second, the pseudo-first order regime implies the respect of several 
conditions. Third, the evaluation of the mass-transfer rate is based on the ozone mass balance quantification at steady state, therefore $C_{G, 0}$ must be significantly lower than $C_{G, i}$ and the reactant consumption must remain negligible. Fourth, the enhancement factor $E$ should be restricted to limit the influence of the gas-phase resistance. All these conditions require the respect of the following numerical criteria which will affect the choice of $C_{G, i}$ and $C_{R}$ :

- (i) $\mathrm{Ha}>5$ (fast regime) with Ha calculated according to Eq. 16;

- (ii) $H a>E_{i} / 2$ (pseudo first order regime) with $E_{i}$ calculated according to Eq. 17 and $C_{L}{ }^{*}$ calculated according to Eq. 18;

- (iii) $C_{G, o} / C_{G, i} \leq 0.8 \Rightarrow C_{G, i} / C_{G, o} \geq 1.25$ to have a sufficient accuracy. $C_{G, i} / C_{G, o}$ can be calculated according to Eq. 21;

- (iv) Steady state duration $\Delta t$ higher than $10 \mathrm{~min}$, with $\Delta t$ calculated from Eq. 28;

- (v) $C_{G, o}$ must be higher than $0.1 \mathrm{~g} \mathrm{Nm}^{-3}\left(\approx 2 \times 10^{-6} \mathrm{~mol} \mathrm{~L}^{-1}\right)$ to be measured by the iodometric method or an on-line analyzer. ${ }^{52}$ Therefore, at $20^{\circ} \mathrm{C}$, the minimal value of $C_{L}^{e q}$ is around $6 \times 10^{-7}$ $\mathrm{mol} \mathrm{L}^{-1}$;

- $\quad$ (vi) $R_{L}>20 \%$ with $R_{L}$ calculated according to Eq. 12 .

The criteria (i), (ii) and (iii) correspond to three inequalities which allow to determine three minimal values of $C_{R}$ :

$C_{R}>\frac{25 k_{L}^{2}}{k D_{L}}$ Eq. 32.

$\sqrt{\frac{k C_{R} D_{L}}{k_{L}^{2}}}<\frac{1}{2}\left(1+\left(1+\frac{R T \sqrt{k C_{R} D_{L}}}{H k_{G}}\right) \frac{C_{R}}{z C_{L}^{e q}}\right)$ assuming $D_{R} \approx D_{L}$ Eq. 33.

$S \frac{R T}{F_{G} H}\left(\frac{1}{k C_{R} D_{L}}+\frac{R T}{H k_{G}}\right)^{-1}>0.25$

Eq. 34. 
Considering a minimal value of $C_{L}{ }^{e q}$ around $6 \times 10^{-7} \mathrm{~mol} \mathrm{~L}^{-1}, C_{R}$ was determined for increasing values of $k$, simulating the experimental conditions applied in this study. In all cases, the criteria (iii) imposed the highest value of $C_{R}$, with a corresponding Hatta number $(=E)$ near 150 . Such a high Hatta number is convenient to neglect the influence of the considered mass-transfer theories (double-film or surface renewal theories) and to respect the criterion (vi), with $R_{L}$ around 0.87 . For increasing values of $k$, the corresponding minimal $C_{R}$ value to fulfill the criteria (i)-(iii) decreases (green straight line, Fig. 7). $k$ values lower than around $10^{4} \mathrm{~L} \mathrm{~mol}^{-1} \mathrm{~s}^{-1}$ (lower limit of the method) would imply $C_{R}>0.1 \mathrm{~mol} \mathrm{~L}^{-1}$, which makes the method hardly applicable in many cases (high reactant consumption and cost, solubility limit, etc.). Then, the maximal value of $C_{G, o}$ (and $C_{G, i}$ from the mass-balance) that can be applied to fulfill the criteria (ii) for each value of $C_{R}$ can be evaluated (blue straight line, Fig. 7). When $C_{R}$ decreases for increasing values of $k$, the maximal values of $C_{G, o}$ and $C_{G, i}$ decrease. High values of $C_{G, o}$ and $C_{G, i}$ are preferred to optimize the analytical precision, using an on-line analyzer (but are not compatible with the iodometric method). In all cases, except when $k>10^{7} \mathrm{~L} \mathrm{~mol}^{-1} \mathrm{~s}^{-1}$, the criteria (iv) and (i) are respected simultaneously. When $k>10^{7} \mathrm{~L} \mathrm{~mol}^{-1} \mathrm{~s}^{-1}$ (upper limit of the method), it becomes impossible to guarantee a pseudo-first order regime which last for at least $10 \mathrm{~min}$. In that case, it is recommended to measure the reactant time course in addition of the ozone mass-balance. 


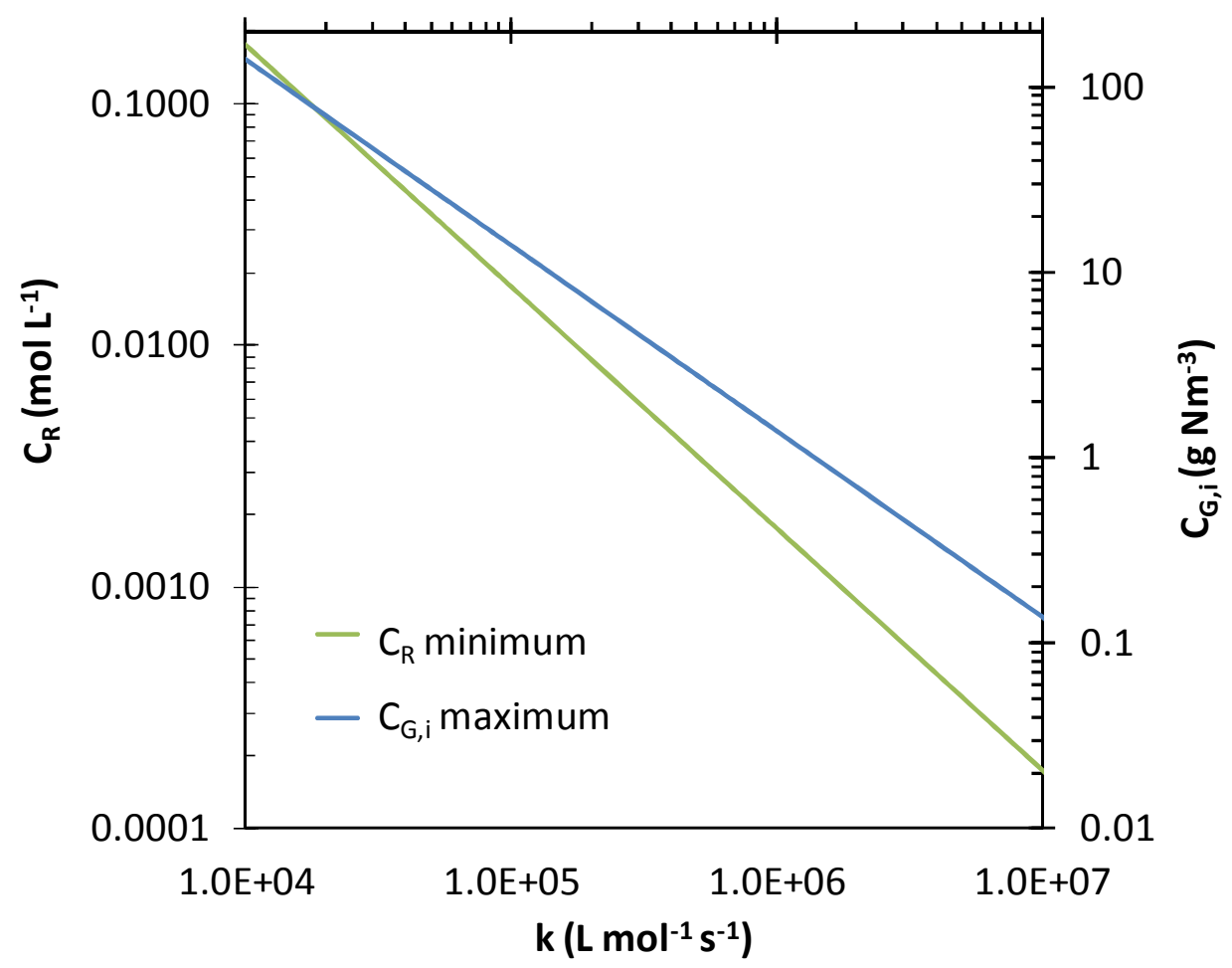

Fig. 7 : Evolution the minimal value of $C_{R}$ and maximal value of $C_{G, i} v s$. $k$ to respect the criteria (i)(vi). These criteria cannot be respected simultaneously below $10^{4}$ and above $10^{7} \mathrm{~L} \mathrm{~mol}^{-1} \mathrm{~s}^{-1}$.

It is possible to apply respectively higher and lower values of $C_{R}$ and $C_{G, i}$ than those summarized in Fig. 7, while checking the criterion (ii). In the one hand, increasing $C_{R}$ allows to enhance the mass-transfer rate and minimize the ratio $C_{G, o} / C_{G, i}$ toward a higher accuracy. On the other hand, it reduces $R_{L}$, which increases the sensitivity of the model to $k_{G}$.

\section{Conclusion}

A methodology to assess the kinetics of fast ozonation reactions by reactive absorption was presented. A jacketed stirred-cell reactor, operated semi-continuously, containing a high concentration of the reactant in solution ( $0.1 \mathrm{M}$ of resorcinol) was used. Stirred-cell reactors appear particularly appealing owing to their easy mathematical modeling, temperature control and flow patterns description. Moreover, the interfacial area corresponds to the flat surface separating both phases, which avoid 
hazardous extrapolation from chemical methods. Nonetheless, the mass-transfer rate is low and the gasphase resistance might be significant and should be considered in the calculation, even using a poorly soluble solute such as ozone. On the one hand, the high reactant concentration was convenient to reach a steady state and to avoid the accumulation of by-products which would significantly interfere. Thus, the mass-transfer rate, and consecutively the reaction rate, were deduced from the ozone mass balance in the gas phase, the reactant and ozone concentrations in solution being respectively constant and negligible. Therefore, liquid phase analyses were unnecessary and only the gas ozone concentration was measured on-line during a typical experiment. On the other hand, the high reactant concentration induces an important reactant consumption. The experiments were performed on the pseudo-first order regime which allows to neglect the influence of $k_{L}$ and reactant diffusion coefficient. The addition of a radical scavenger (such as tert-butanol) might be necessary to avoid interferences from the radicals formed during the ozone decomposition.

The gas-phase and liquid-phase mass-transfer coefficients were advantageously directly measured respectively through the ozone absorption in the surface reaction regime and by physical absorption. The ozone-resorcinol reaction rate constant at acidic $\mathrm{pH}$ was consistent with the values reported in previous studies. $^{20,49,50}$ The results emphasized the high sensitivity of the model to the experimental conditions and ozone physicochemical properties, especially the solubility and diffusivity, which are rather uncertain.

The applicability of the method was discussed. This method can be applied for reaction rate constant included in the range $10^{4}-10^{7} \mathrm{~L} \mathrm{~mol}^{-1} \mathrm{~s}^{-1}$, covering a wide variety of chemical families (sulfur compounds, amines, amino-acids, phenols and phenolates, some pesticides, pharmaceuticals or dyes, etc.). However, this technique cannot be applied to volatile reactant which would be stripped in the gas phase. 


\section{Acknowledgments}

Thom Thi DANG received financial supports from the Vietnam Ministry of Education and Training (Grant N4294) and Campus France (Grant N 793312F and 793315L).

We gratefully acknowledge M. Pierre Largillière for his help for the pilot design.

\section{Supporting Information}

S1: Scheme and pictures of the stirred cell-reactor and experimental set-up

S2: Gas flow rate correction - ozone concentration compensation

S3: Ozone Henry's law constant dependence on the temperature

This material is available free of charge via the Internet at http://pubs.acs.org. 


\section{Nomenclature}

$C_{G}$ : ozone concentration in the gas phase (read in $\mathrm{g} \mathrm{Nm}^{-3}$ and converted in $\mathrm{mol} \mathrm{m}^{-3}$ )

$C_{L}$ : ozone concentration in the liquid phase $\left(\mathrm{mol} \mathrm{m}^{-3}\right)$

$C_{R}$ : reactant bulk concentration $\left(\mathrm{mol} \mathrm{L}^{-1}\right)$

$d_{t}$ : turbine diameter $(\mathrm{m})$

$D_{L}$ : ozone diffusion coefficient at infinite dilution in the liquid phase $\left(\mathrm{m}^{2} \mathrm{~s}^{-1}\right)$

$D_{G}$ : ozone diffusion coefficient at infinite dilution in the gas phase $\left(\mathrm{m}^{2} \mathrm{~s}^{-1}\right)$

$D_{R}$ : reactant diffusion coefficient at infinite dilution in the liquid phase $\left(\mathrm{m}^{2} \mathrm{~s}^{-1}\right)$

dJ: mass-transfer rate $\left(\mathrm{mol} \mathrm{s}^{-1}\right)$

$E$ : enhancement factor (dimensionless)

$E_{i}$ : instantaneous enhancement factor

EF: error function (according to Eq. 11)

El: elasticity index (dimensionless)

$F_{G}$ : gas flow rate $\left(\mathrm{m}^{3} \mathrm{~s}^{-1}\right)$

$H$ : ozone Henry's law constant $\left(\mathrm{Pa} \mathrm{m} \mathrm{mol}^{-1}\right)$

Ha: Hatta number (dimensionless)

I: any input of the model

$k$ : second-order reaction rate constant referred to the balanced equation $14\left(\mathrm{~L} \mathrm{~mol}^{-1} \mathrm{~s}^{-1}\right)$

$k_{G}$ : gas-phase mass-transfer coefficient $\left(\mathrm{m} \mathrm{s}^{-1}\right)$

$k_{L}$ : liquid-phase mass-transfer coefficient $\left(\mathrm{m} \mathrm{s}^{-1}\right)$

$K_{L}$ : overall liquid-phase mass-transfer coefficient $\left(\mathrm{m} \mathrm{s}^{-1}\right)$

$M_{\mathrm{O}_{3}}$ : ozone molar mass $\left(\mathrm{g} \mathrm{mol}^{-1}\right.$ )

$N$ : stirrer speed $\left(\mathrm{s}^{-1}\right)$

$O$ : any output of the model

$P$ : pressure in the reactor (bar)

$\mathrm{R}$ : ideal gas constant $\left(8.314 \mathrm{~J} \mathrm{~mol}^{-1} \mathrm{~K}^{-1}\right.$ )

$S c_{L}=\frac{\mu_{L}}{\rho_{L} D_{L}}$, Schmidt number of the liquid (dimensionless)

$R e_{L}:=\frac{\rho_{L} N d_{t}{ }^{2}}{\mu_{L}}$, Reynolds number of the liquid (dimensionless)

$R_{L}$ : relative liquid-side resistance (\%) 
S: gas-liquid interfacial area $\left(\mathrm{m}^{2}\right)$

$S h_{L}:=\frac{k_{L} d_{t}}{D_{L}}$, Sherwood number of the liquid(dimensionless)

$t$ : time (s)

$T:$ Temperature $\left(\mathrm{K}\right.$ or $\left.{ }^{\circ} \mathrm{C}\right)$

$V:$ liquid volume $\left(\mathrm{m}^{3}\right)$

$\mathrm{V}_{\mathrm{m}}$ : molar volume $\left(22.4 \mathrm{NL} \mathrm{mol}^{-1}\right)$

$z$ : stoichiometric number (dimensionless)

\section{Greek letters:}

$\mu$ : dynamic viscosity (Pa s)

$\Delta t$ : time necessary to observe a decreasing of $C_{R}$ of $5 \%$ according to Eq. 28 (s or min)

$\rho$ : density $\left(\mathrm{kg} \mathrm{m}^{-3}\right)$

\section{Subscripts:}

calib: relative to the conditions of calibration of the flow meter

G: relative to the gas

i: at the inlet

L: relative to the liquid

$\mathrm{N}$ : relative to the normal conditions of temperature and pression

o: at the outlet

$\mathrm{R}$ : relative to the reactant

\section{Superscripts:}

*: at the interface

eq: at the equilibrium 


\section{References}

(1) Von Sonntag, C.; Von Gunten, U. Chemistry of Ozone in Water and Wastewater Treatment: From Basic Principles to Applications; IWA Publishing: 2012.

(2) Von Gunten, U. Ozonation of Drinking Water: Part I. Oxidation Kinetics and Product Formation. Water Res. 2003, 37, 1443.

(3) Beltrán, F. J. Ozone Reaction Kinetics for Water and Wastewater Systems; Lewis Publisher: Boca Raton, 2004.

(4) Navarro-Laboulais, J.; Capablanca, L.; Abad, A.; Cardona, S. C.; López, F.; Torregrosa, J. I. Mathematical Model for Monitoring Gas-Liquid Reactors by Means of Continuous Flow Analysis. Ozone: Sci. Eng. 2006, 28, 17.

(5) Aieta, E. M.; Roberts, P. V. Application of Mass-Transfer Theory to the Kinetics of a Fast Gas-Liquid Reaction: Chlorine Hydrolysis. Environ. Sci. Technol. 1986, 20, 44.

(6) Ebrahimi, S.; Picioreanu, C.; Kleerebezem, R.; Heijnen, J. J.; van Loosdrecht, M. C. M. Rate-Based Modelling of $\mathrm{SO}_{2}$ Absorption into Aqueous $\mathrm{NaHCO}_{3} / \mathrm{Na}_{2} \mathrm{CO}_{3}$ Solutions Accompanied by the Desorption of $\mathrm{CO}_{2}$. Chem. Eng. Sci. 2003, 58, 3589.

(7) Jing, G.; Zhou, L.; Zhou, Z. Characterization and Kinetics of Carbon Dioxide Absorption into Aqueous Tetramethylammonium Glycinate Solution. Chem. Eng. J. 2012, 181-182, 85.

(8) Jia, Y.; Zhong, Q.; Fan, X.; Wang, X. Kinetics of Oxidation of Total Sulfite in the Ammonia-Based Wet Flue Gas Desulfurization Process. Chem. Eng. J. 2010, 164, 132. 
(9) Sema, T.; Naami, A.; Fu, K.; Edali, M.; Liu, H.; Shi, H.; Liang, Z.; Idem, R.; Tontiwachwuthikul, P. Comprehensive Mass Transfer and Reaction Kinetics Studies of $\mathrm{CO}_{2}$ Absorption into Aqueous Solutions of Blended MDEA-MEA. Chem. Eng. J. 2012, 209, 501.

(10) Kucka, L.; Kenig, E. Y.; Gorak, A. Kinetics of the Gas-Liquid Reaction between Carbon Dioxide and Hydroxide lons. Ind. Eng. Chem. Res. 2002, 41, 5952.

(11) Vaidya, P. D.; Kenig, E. Y. Absorption of $\mathrm{CO}_{2}$ into Aqueous Blends of Alkanolamines Prepared from Renewable Resources. Chem. Eng. Sci. 2007, 62, 7344.

(12) Vaidya, P. D.; Kenig, E. Y. A Study on $\mathrm{CO}_{2}$ Absorption Kinetics by Aqueous Solutions of N,NDiethylethanolamine and N-Ethylethanolamine. Chem. Eng. Technol. 2009, 32, 556.

(13) Versteeg, G.; Van Dijck, L.; Van Swaaij, W. On the Kinetics between $\mathrm{CO}_{2}$ and Alkanolamines Both in Aqueous and Non-Aqueous Solutions. An Overview. Chem. Eng. Commun. 1996, 144, 113.

(14) Littel, R.; Van Swaaij, W.; Versteeg, G. Kinetics of Carbon Dioxide with Tertiary Amines in Aqueous Solution. AlChE J. 1999, 36, 1633.

(15) Vilmain, J.-B.; Courousse, V.; Biard, P.-F.; Azizi, M.; Couvert, A. Kinetic Study of Hydrogen Sulfide Absorption in Aqueous Chlorine Solution. Chem. Eng. Res. Des. 2014, 92, 191.

(16) Kucka, L.; Richter, J.; Kenig, E. Y.; Górak, A. Determination of Gas-Liquid Reaction Kinetics with a Stirred Cell Reactor. Sep. Purif. Technol. 2003, 31, 163.

(17) Vaidya, P. D.; Kenig, E. Y. Gas-Liquid Reaction Kinetics: A Review of Determination Methods. Chem. Eng. Commun. 2007, 194, 1543. 
(18) Beltrán, F. J.; Fernández, L. A.; Álvarez, P.; Rodriguez, E. Comparison of Ozonation Kinetic Data from Film and Danckwerts Theories. Ozone: Sci. Eng. 1998, 20, 403.

(19) Sotelo, J. L.; Beltrán, F. J.; Gonzalez, M. Ozonation of Aqueous Solutions of Resorcinol and Phloroglucinol. 1. Stoichiometry and Absorption Kinetic Regime. Ind. Eng. Chem. Res. 1990, 29, 2358.

(20) Sotelo, J. L.; Beltrán, F. J.; Gonzalez, M.; Garcia-Araya, J. F. Ozonation of Aqueous Solutions of Resorcinol and Phloroglucinol. 2. Kinetic Study. Ind. Eng. Chem. Res. 1991, 30, 222.

(21) Cardona, S. C.; López, F.; Abad, A.; Navarro-Laboulais, J. On Bubble Column Reactor Design for the Determination of Kinetic Rate Constants in Gas-Liquid Systems. Can. J. Chem. Eng. 2010, 88, 491.

(22) Beltrán, F. J.; Alvarez, P. M.; Legube, B.; Allemane, H. Chemical Degradation of Aldicarb in Water Using Ozone. J. Chem. Technol. Biotechnol. 1995, 62, 272.

(23) Rinker, E. B.; Ashour, S. S.; Johnson, M. C.; Kott, G. J.; Rinker, R. G.; Sandall, O. C. Kinetics of the Aqueous-Phase Reaction between Ozone and 2,4,6-Trichlorophenol. AlChE J. 1999, 45, 1802.

(24) Augugliaro, V.; Rizzuti, L. The pH Dependence of the Ozone Absorption Kinetics in Aqueous Phenol Solutions. Chem. Eng. Sci. 1978, 33, 1441.

(25) Littel, R.; Versteeg, G.; Van Swaaij, W. Physical Absorption into Non-Aqueous Solutions in a Stirred Cell Reactor. Chem. Eng. Sci. 1991, 46, 3308.

(26) Versteeg, G.; Blauwhoff, P.; Van Swaaij, W. The Effect of Diffusivity on Gas-Liquid Mass Transfer in Stirred Vessels. Experiments at Atmospheric and Elevated Pressures. Chem. Eng. Sci. 1987, 42, 1103.

(27) Luzi, C.; Bressa, S.; Mazza, G.; Barreto, G. A Supporting Formulation for Introducing Gas-Liquid Reactions. Ed. Chem. Eng. 2014, 9, 50. 
(28) Bin, A. K.; Roustan, M. Mass Transfer in Ozone Reactors. Presented at the IOA International specialised symposium, fundamental and engineering concepts for ozone reactor design, Toulouse, 2000; pp 99-131.

(29) Mandel, P. Modelling Ozonation Processes for Disinfection by-Product Control in Potable Water Treatment : From Laboratory to Industrial Units. Ph.D. dissertation, Université de Rennes 1, Rennes, 2010. https://tel.archives-ouvertes.fr/tel-00564767/document (accessed July 2016).

(30) Thienpont, B.; Tingaud-Sequeira, A.; Prats, E.; Barata, C.; Babin, P. J.; Raldúa, D. Zebrafish Eleutheroembryos Provide a Suitable Vertebrate Model for Screening Chemicals That Impair Thyroid Hormone Synthesis. Environ. Sci. Technol. 2011, 45, 7525.

(31) BMT Messtechnik GmBH, Technote Tn-1: High Concentration Photometric Ozone Measurement Palimpset. http://www.bmt-berlin.de/wp-content/uploads/TN1_OzoneHandbook.pdf (Accessed July 2016).

(32) Bader, H.; Hoigne, J. Determination of Ozone in Water by the Indigo Method. Water Res. 1981, 15, 1573.

(33) Ortiz, A.; Galán, L. M.; Gorri, D.; de Haan, A. B.; Ortiz, I. Kinetics of Reactive Absorption of Propylene in RTIL-Ag ${ }^{+}$Media. Sep. Purif. Technol. 2010, 73, 106.

(34) Roustan, M. Transferts Gaz-Liquide Dans Les Procédés De Traitement Des Eaux Et Des Effluents Gazeux. Lavoisier: Paris, 2003.

(35) Hoffmann, A.; Mackowiak, J.; Gorak, A.; Haas, M.; Loning, J.; Runowski, T.; Hallenberger, K. Standardization of Mass Transfer Measurements: A Basis for the Description of Absorption Processes. Chem. Eng. Res. Des. 2007, 85, 40. 
(36) Rejl, J.; Linek, V.; Moucha, T.; Valenz, L. Methods Standardization in the Measurement of MassTransfer Characteristics in Packed Absorption Columns. Chem. Eng. Res. Des. 2009, 87, 695.

(37) Liu, Q.; Schurter, L. M.; Muller, C. E.; Aloisio, S.; Francisco, J. S.; Margerum, D. W. Kinetics and Mechanisms of Aqueous Ozone Reactions with Bromide, Sulfite, Hydrogen Sulfite, lodide, and Nitrite Ions. Inorg. Chem. 2001, 40, 4436.

(38) DeCoursey, W. J. Absorption with Chemical Reaction: Development of a New Relation for the Danckwerts Model. Chem. Eng. Sci. 1974, 29, 1867.

(39) Biard, P.-F.; Couvert, A. Overview of Mass Transfer Enhancement Factor Determination for Acidic and Basic Compounds Absorption in Water. Chem. Eng. J. 2013, 222, 444.

(40) Johnson, P. N.; Davis, R. A. Diffusivity of Ozone in Water. J. Chem. Eng. Data 1996, 41, 1485.

(41) Masschelein, W. J. Fundamental Properties of Ozone in Relation to Water Sanitation and Environmental Applications. Presented at the IOA International specialised symposium, fundamental and engineering concepts for ozone reactor design, Toulouse, 2000; pp 1-21.

(42) Fuller, E. C.; Crist, R. H. The Rate of Oxidation of Sulfite lons by Oxygen. J. Am. Chem. Soc. 1941, 63, 1644.

(43) Wilkinson, P. M.; Doldersum, B.; Cramers, P. H.; Van Dierendonck, L. L. The Kinetics of Uncatalyzed Sodium Sulfite Oxidation. Chem. Eng. Sci. 1993, 48, 933.

(44) Biard, P.-F.; Werghi, B.; Soutrel, I.; Orhand, R.; Couvert, A.; Denicourt-Nowicki, A.; Roucoux, A. Efficient Catalytic Ozonation by Ruthenium Nanoparticles Supported on $\mathrm{SiO}_{2}$ or $\mathrm{TiO}_{2}$ : Towards the Use of a Non-Woven Fiber Paper as Original Support. Chem. Eng. J. 2016, 289, 374. 
(45) Biń, A. K. Ozone Solubility in Liquids. Ozone: Sci. Eng. 2006, 28, 67.

(46) Ferre-Aracil, J.; Cardona, S.; Navarro-Laboulais, J. Determination and Validation of Henry's Constant for Ozone in Phosphate Buffers Using Different Analytical Methodologies. Ozone: Sci. Eng. 2015, 37, 106.

(47) Mizuno, T.; Tsuno, H. Evaluation of Solubility and the Gas-Liquid Equilibrium Coefficient of High Concentration Gaseous Ozone to Water. Ozone: Sci. Eng. 2010, 32, 3.

(48) Massman, W. J. A Review of the Molecular Diffusivities of $\mathrm{H}_{2} \mathrm{O}, \mathrm{CO}_{2}, \mathrm{CH}_{4}, \mathrm{CO}, \mathrm{O}_{3}, \mathrm{SO}_{2}, \mathrm{NH}_{3}, \mathrm{~N}_{2} \mathrm{O}$, $\mathrm{NO}$, and $\mathrm{NO}_{2}$ in Air, $\mathrm{O}_{2}$ and $\mathrm{N}_{2}$ near STP. Atmos. Environ. 1998, 32, 1111.

(49) Hoigne, J.; Bader, H. Rate Constants of Reactions of Ozone with Organic and Inorganic Compounds in Water- II. Dissociating Organic Compounds. Water Res. 1983, 17, 185.

(50) Gurol, M. D.; Nekouinaini, S. Kinetic Behavior of Ozone in Aqueous Solutions of Substituted Phenols. Ind. Eng. Chem. Fund. 1984, 23, 54.

(51) Sotelo, J. L.; Beltrán, F. J.; Benitez, F. J.; Beltrán-Heredia, J. Henry's Law Constant for the OzoneWater System. Water Res. 1989, 23, 1239.

(52) Rakness, K.; Gordon, G.; Langlais, B.; Masschelein, W.; Matsumoto, N.; Richard, Y.; Robson, C. M.; Somiya, I. Guideline for Measurement of Ozone Concentration in the Process Gas from an Ozone Generator. Ozone: Sci. Eng. 1996, 18, 209. 


\section{List of Figure captions}

Figure 1: Process Flow Diagram (PFD) of the experimental set-up (A picture is presented as Supporting Information, Fig. S1).

Figure 2: Time course of the ozone gas (a) and liquid (b) concentrations. The straight lines correspond to the model (Eqs 7 and 8 ) using $k_{L}$ reported in Table 2.

Figure 3: Evolution of $k_{L}$ vs. the temperature considering different correlations used to calculate the ozone Henry's law constant. The model is deduced from Eq. 27 with $C_{1}=0.542, C_{2}=0.11$ and $C_{3}=0.66$.

Figure 4: Evolution of $k$ vs the temperature considering the Ferre-Aracil et al. and Perry's correlations to calculate the ozone Henry's law constant. The values of Sotelo et al. were extrapolated between 20 and

$35^{\circ} \mathrm{C}$ from the data at 1,10 and $20^{\circ} \mathrm{C}$ using the Arrhenius law (Fig. 5). ${ }^{20}$ The error bars correspond to the standard deviation of the experimental points.

Figure 5: Plot of $\ln (k)$ vs. 1/RT (Arrhenius law linearization) considering the Ferre-Aracil et al. and Perry's correlations to calculate the ozone Henry's law constant and with the values of $k$ determined by Sotelo et al. $^{20}$

Figure 6: Plot of the elasticity index of the model inputs vs. the value of the output (reaction rate constant $k$ ).

Figure 7: Evolution the minimal value of $C_{R}$ and maximal value of $C_{G, i}$ vs. $k$ to respect the criteria (i)-(vi). These criteria cannot be respected simultaneously below $10^{4}$ and above $10^{7} \mathrm{~L} \mathrm{~mol}^{-1} \mathrm{~s}^{-1}$. 


\section{For Table of Contents Only}

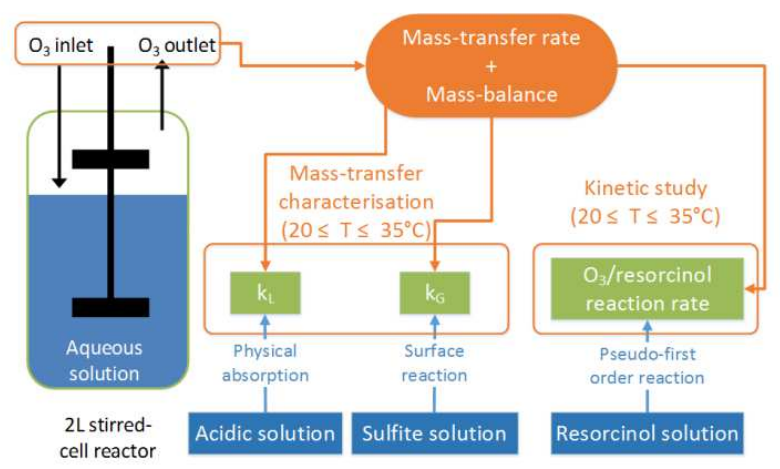

